\title{
SAND94-1497
}

Unlimited Release

Printed July 12, 1994

FINAL REPORT SUBMITTED

to

National Aeronautics and Space Administration

Office of Space Science

Planetary Materials and Geochemistry Program

\section{APPLICATION OF NMR SHOCK BAROMETER \\ TO NATURALLY SHOCKED MINERALS}

\author{
Randall T. Cygan \\ Geochemistry Department \\ Sandia National Laboratories \\ Albuquerque, NM 87185-0750 \\ and \\ Mark B. Boslough \\ Experimental Impact Physics Department \\ Sandia National Laboratories \\ Albuquerque, NM 87185-0821
}

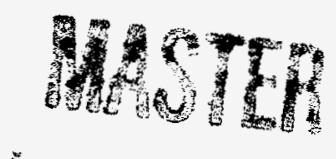




\begin{abstract}
The shock-loading of natural materials by an impact, such as a comet or meteorite, can result in the formation of modified and altered phases in the target rock. In order to characterize the resulting material and to evaluate the extent of shock modification, we have used nuclear magnetic resonance (NMR) spectroscopy to examine several natural and experimentally shocked minerals. We use NMR spectroscopy to characterize the formation of high pressure silica polymorphs and amorphous material associated with the shocked Coconino Sandstone from Meteor Crater, Arizona. Five samples of the sandstone were obtained from several locations at the crater to represent a range of shock conditions associated with the hypervelocity impact of a 30 meter-diameter meteorite. The NMR spectra for these powdered materials exhibit peaks assigned to quartz, coesite, stishovite, and glass. A new resonance, identified as a densified form of amorphous silica with silicon in tetrahedra with one hydroxyl group, is observed for two of the moderately shocked samples. Experimental shock-loading of dry and water-saturated Coconino Sandstone powders provides shock-metamorphosed material that exhibit broadening of NMR resonances with increasing shock pressure, but no evidence of the new dense silica phase.
\end{abstract}




\section{DISCLAIMER}

This report was prepared as an account of work sponsored by an agency of the United States Government. Neither the United States Government nor any agency thereof, nor any of their employees, make any warranty, express or implied, or assumes any legal liability or responsibility for the accuracy, completeness, or usefulness of any information, apparatus, product, or process disclosed, or represents that its use would not infringe privately owned rights. Reference herein to any specific commercial product, process, or service by trade name, trademark, manufacturer, or otherwise does not necessarily constitute or imply its endorsement, recommendation, or favoring by the United States Government or any agency thereof. The views and opinions of authors expressed herein do not necessarily state or reflect those of the United States Government or any agency thereof. 


\section{DISCLAIMER}

Portions of this document may be illegible in electronic image products. Images are produced from the best available original document. 
TABLE OF CONTENTS

ABSTRACT …........................................................................ ii

TABLE OF CONTENTS .................................................................. iii

LIST OF FIGURES …...................................................................... iv

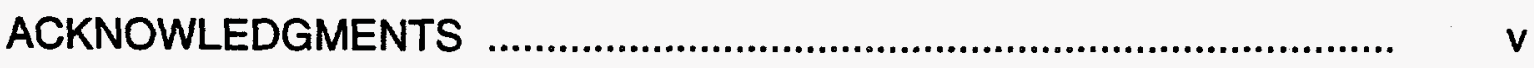

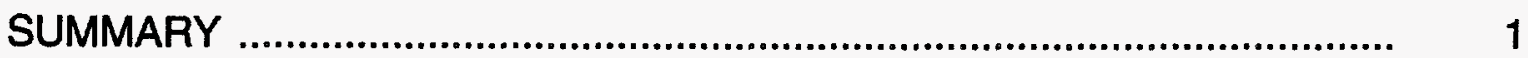

PROJECT RESULTS ......................................................................

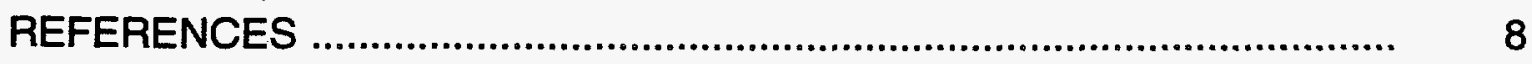

LIST OF PUBLISHED PAPERS .................................................... 9

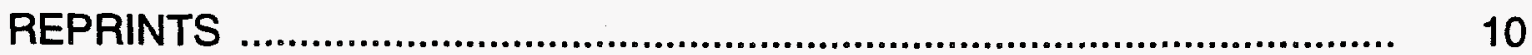

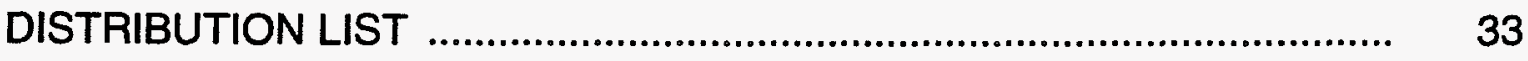




\section{LIST OF FIGURES}

$1{ }^{29} \mathrm{Si}$ NMR spectra of five shocked Coconino Sandstone samples. Resonance identifications are $(Q)$ quartz, $(C)$ coesite, $(S)$ stishovite, (A) $Q^{4}$ sites in amorphous silica, and (D) $Q^{3}$ (one $\mathrm{OH}$ ) silicon sites in a densified form of hydroxylated amorphous silica. Sample numbers are those of Kieffer (1971).

$2{ }^{29}$ Si NMR spectra of unshocked and experimentally-shocked (dry and wet) Coconino Sandstone samples. MAS (all Si sites) and CPMAS (hydrated Si species) spectra are presented for each sample. Arrows denote approximate chemical shift observed in Boslough et al. (1993) and Cygan et al. (1994a) for quartz (Q), coesite (C), clay, and hydrated amorphous silica, including $Q^{3}$ (one $\mathrm{OH}$ ) and $\mathrm{Q}^{2}$ (two $\mathrm{OH}$ ) silicon sites.

3 Laser Raman spectrum for material recovered from the high temperature $22 \mathrm{GPa}$ shock of water-saturated Coconino Sandstone. The presence of vicinal silanol groups is suggested by the bands in the $3600 \mathrm{~cm}^{-1}$ region. 


\section{ACKNOWLEDGMENTS}

Roger Assink and R. James Kirkpatrick are acknowledged for their major contributions regarding NMR spectroscopy. Roger performed and evaluated the NMR relaxation experiments and Jim provided invaluable expertise in the interpretation of the NMR spectra. We are grateful for the efforts of Gary Turner in obtaining the MAS NMR spectra and Marvin Banks and Edward Dunbar in performing the shock recovery experiments. Additional technical support and scientific comments were provided by Martin Carr, William Casey, Michael Eatough, Mary Gonzales, Robert Graham, Charles Hills, Paul Hlava, Susan Kieffer, John McHone, Bruno Morosin, and Henry Westrich. Patrick Brady and Henry Westrich provided comprehensive reviews and suggestions for improving the final report. This research was supported by the U.S. Department of Energy under contract DE-AC04-94AL85000 with funding from the Planetary Materials and Geochemistry Program of the National Aeronautics and Space Administration. 


\section{SUMMARY}

The objective of the present research is to quantify the effect of shock-loading experienced by silicate minerals subjected to natural impact. NMR spectroscopy is used to analyze natural samples, primarily quartz, obtained from known impact sites. The NMR spectral characteristics of the minerals is used to estimate the peak shock pressures and compare the results to a previous experimental calibration of the NMR shock barometer. NMR spectroscopy can also identify high pressure mineral polymorphs, the hydration state of amorphous phases, and evaluate the structural state of diaplectic and fused glasses associated with the terrestrial impacts. The primary objectives of this project have been: 1 ) determine if and how the method can be applied to shocked quartz specimens form natural impacts, and 2) investigate the usefulness of NMR spectroscopy as a screening tool to identify shocked material in samples of unknown origin.

The initial phase for this project has emphasized the characterization of shocked samples from Meteor Crater, Arizona and a comparison with samples obtained by the experimental shock-loading of Coconino Sandstone under dry and wet conditions. Our NMR results of the naturally-shocked Coconino Sandstone support the initial classification scheme of Kieffer based on X-ray diffraction and TEM analyses. We were able to characterize the different states of shocked amorphous silica associated with five different levels of shock loading. A new phase (a densified form of hydrated amorphous silica) has been identified by the NMR technique for a moderately-shocked sample. The experimentally-shocked samples exhibit NMR spectral broadening for both quartz and clay with increasing shock pressure. Deconvolution analysis suggests the amorphous component associated with the wet samples is more dense than the dry samples. Raman spectroscopic analysis indicates the formation of a hydrated silica phase represented by vicinal silanol groups.

This NASA project was started in June 1992 with funding from the Office of Space Science and the Planetary Materials and Geochemistry Program. The project was renewed the following year with funding provided through May 1994. This final report covers the research performed during this funding period. Additional funding to renew this project starting in June 1994 has been approved by the Washington DC NASA office. Randall T. Cygan (Sandia National Labs) 
and Mark B. Boslough (Sandia National Labs) are the principal investigators with assistance from Roger A. Assink (Sandia National Labs) and R. James

Kirkpatrick (University of Illinois). 


\section{PROJECT RESULTS}

Under the present funding from the Planetary Materials and Geochemistry Program at NASA, we applied NMR spectroscopy to five naturally-shocked Coconino Sandstone samples from Meteor Crater, Arizona. Figure 1 provides a summary of these ${ }^{29} \mathrm{Si}$ NMR results and notes the presence of the silica polymorphs and the dense hydrated phase (D) (see reprints). Over the past year, we have also collected cross-polarization NMR data, we obtained spectra using different pulse delay times for gross comparison of relaxation times of various phases, and we have applied extensive deconvolution analysis. The spectra strongly correlate with Kieffer's (1971) classification scheme for various stages of shock metamorphism. They also yield strong evidence for a new shock-produced amorphous phase, as discussed in the accompanying reprints (Boslough et al., 1993; Cygan et al., 1994a).

We have now performed six more shock recovery experiments on Coconino Sandstone, at peak pressures of $7.5,16$, and $22 \mathrm{GPa}$. For each pressure level, we shocked two samples, one dry and one fully saturated with water. We obtained NMR spectra from the shocked specimens, and found very little difference between the initially wet and dry samples (see Figure 2 and reprints; Cygan et al, 1994b). We also found that the peaks broaden as a function of shock pressure, independent of water content, in much the same way as the synthetic quartz powders do in our earlier shock barometry work.

Kieffer (1971) provided a strong argument that many of the shock metamorphic features in Coconino Sandstone are attributable to the presence of groundwater. However, our experimentally-shocked sample spectra bear very little resemblance to the spectra from naturally-shocked samples from Kieffer, in that none of the high pressure phases nor dense hydroxylated glass are present. We suspect that the strongest parameter responsible for this difference is the duration of the shock pulse, which is measured in microseconds for the experimental shock, and tens or more of milliseconds for the natural shock at Meteor Crater (and it is worth noting that quartz grains at the K/T impact may have experienced high pressure for times of several seconds). Laser Raman spectroscopy of the experimentally-shocked wet sandstone, however, does suggest the occurrence of a phase characterized by coordinated silanol groups. 


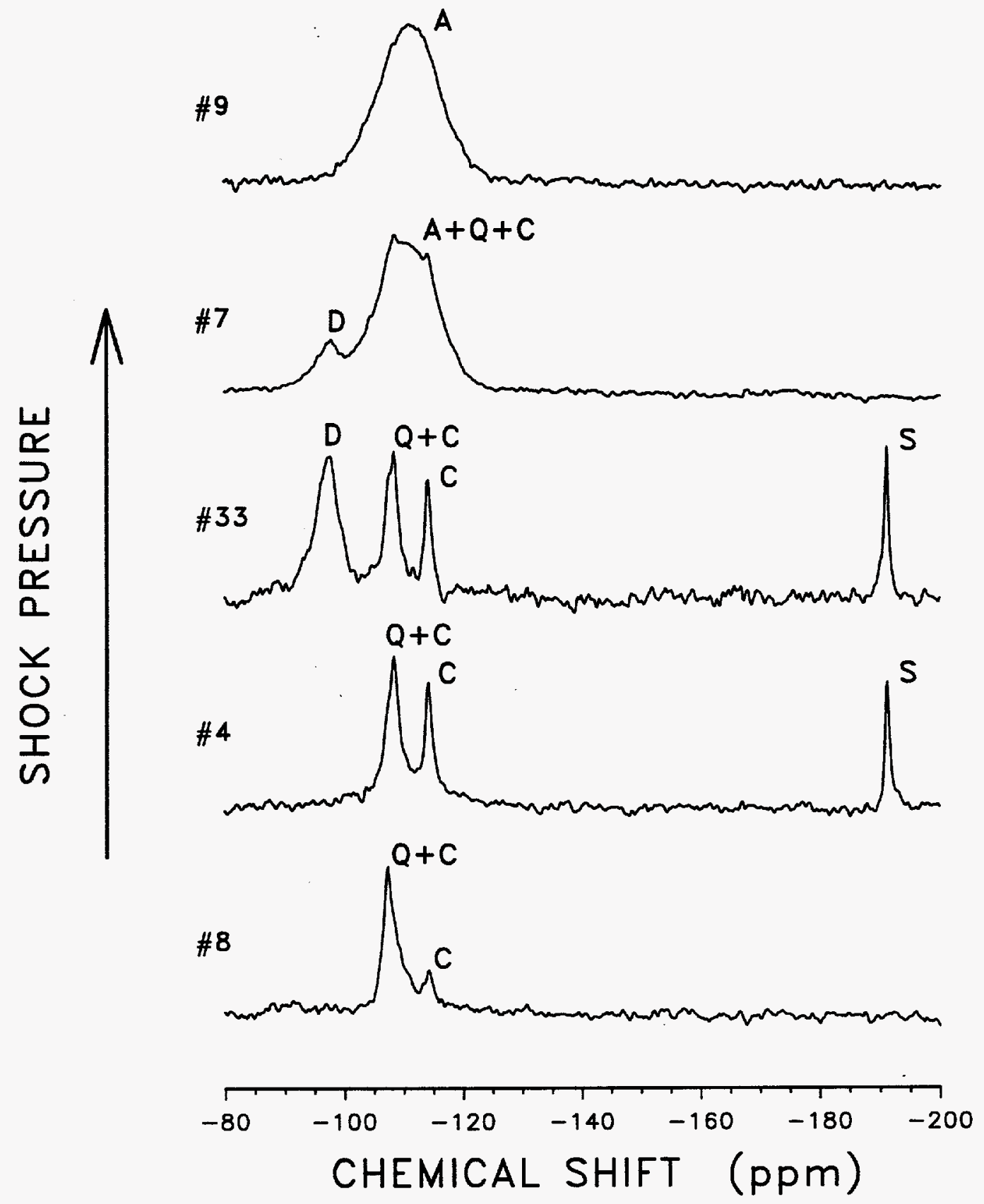

Figure 1. ${ }^{29} \mathrm{Si}$ NMR spectra of five shocked Coconino Sandstone samples. Resonance identifications are $(Q)$ quartz, (C) coesite, (S) stishovite, $(A) Q^{4}$ sites in amorphous silica, and (D) $Q^{3}$ (one $O H$ ) silicon sites in a densified form of hydroxylated amorphous silica. Sample numbers are those of Kieffer (1971). 


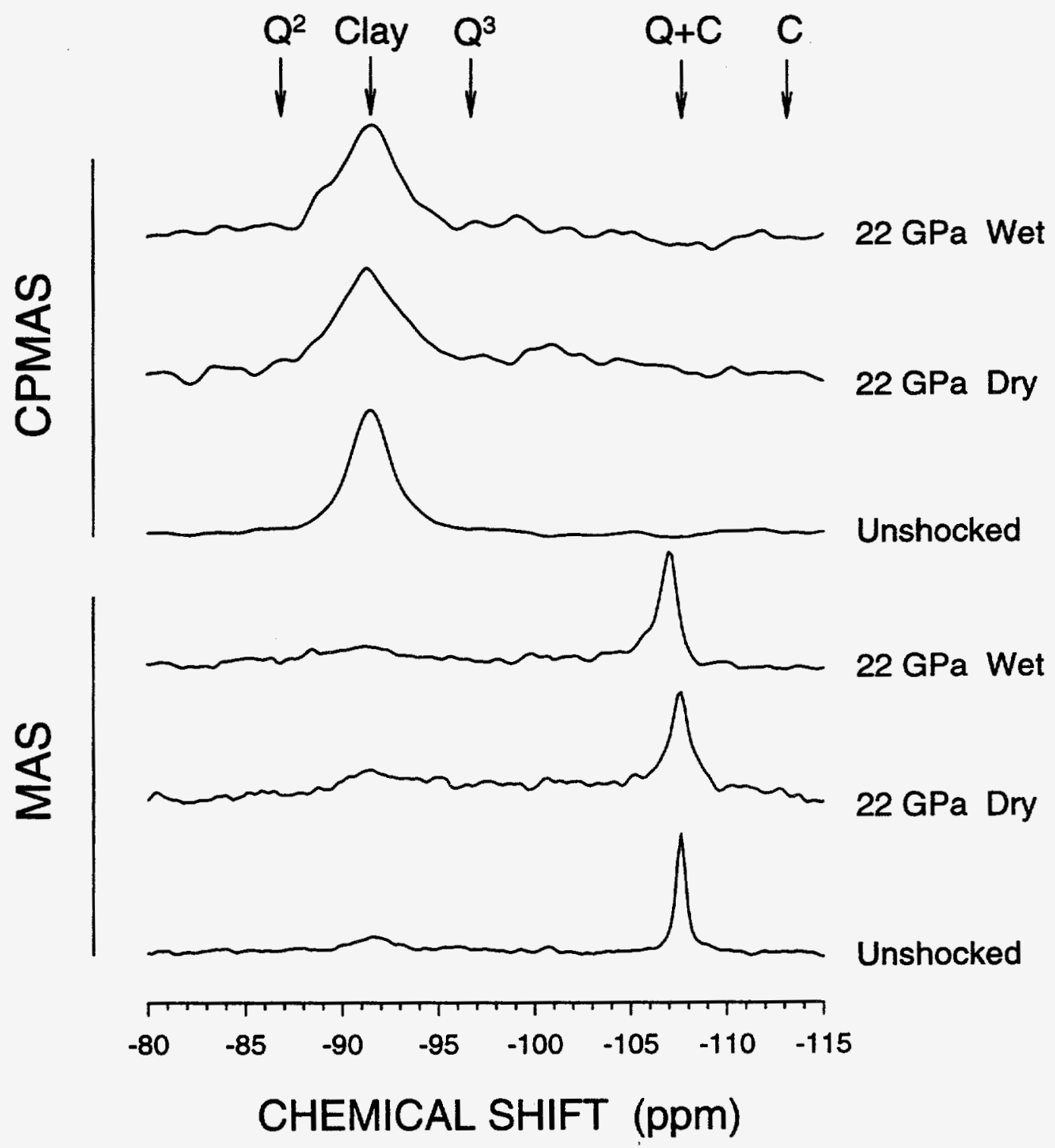

Figure 2. ${ }^{29}$ Si NMR spectra of unshocked and experimentally-shocked (dry and wet) Coconino Sandstone samples. MAS (all Si sites) and CPMAS (hydrated Si species) spectra are presented for each sample. Arrows denote approximate chemical shift observed in Boslough et al. (1993) and Cygan et al. (1994a) for quartz $(Q)$, coesite $(C)$, clay, and hydrated amorphous silica, including $Q^{3}$ (one $\mathrm{OH})$ and $\mathrm{Q}^{2}$ (two $\left.\mathrm{OH}\right)$ silicon sites. 
Figure 3 notes the presence of vicinal silanol groups associated with the silica phase.

We also performed two more recovery experiments on the synthetic quartz powder of our original study. These experiments were done on a $30-\mathrm{mm}$-bore propellant gun. Peak pressures obtained were 19 and $39 \mathrm{GPa}$. NMR spectral analysis of these samples is pending; we will use them for independent confirmation of our peak-width versus peak pressure dependence, and for intercomparison of various shock recovery methods.

Detailed summaries of the experimental procedures, results, and applications of NMR spectroscopy for examining shocked minerals are provided in the attached eight (8) reprints of conference abstracts and journal articles. 


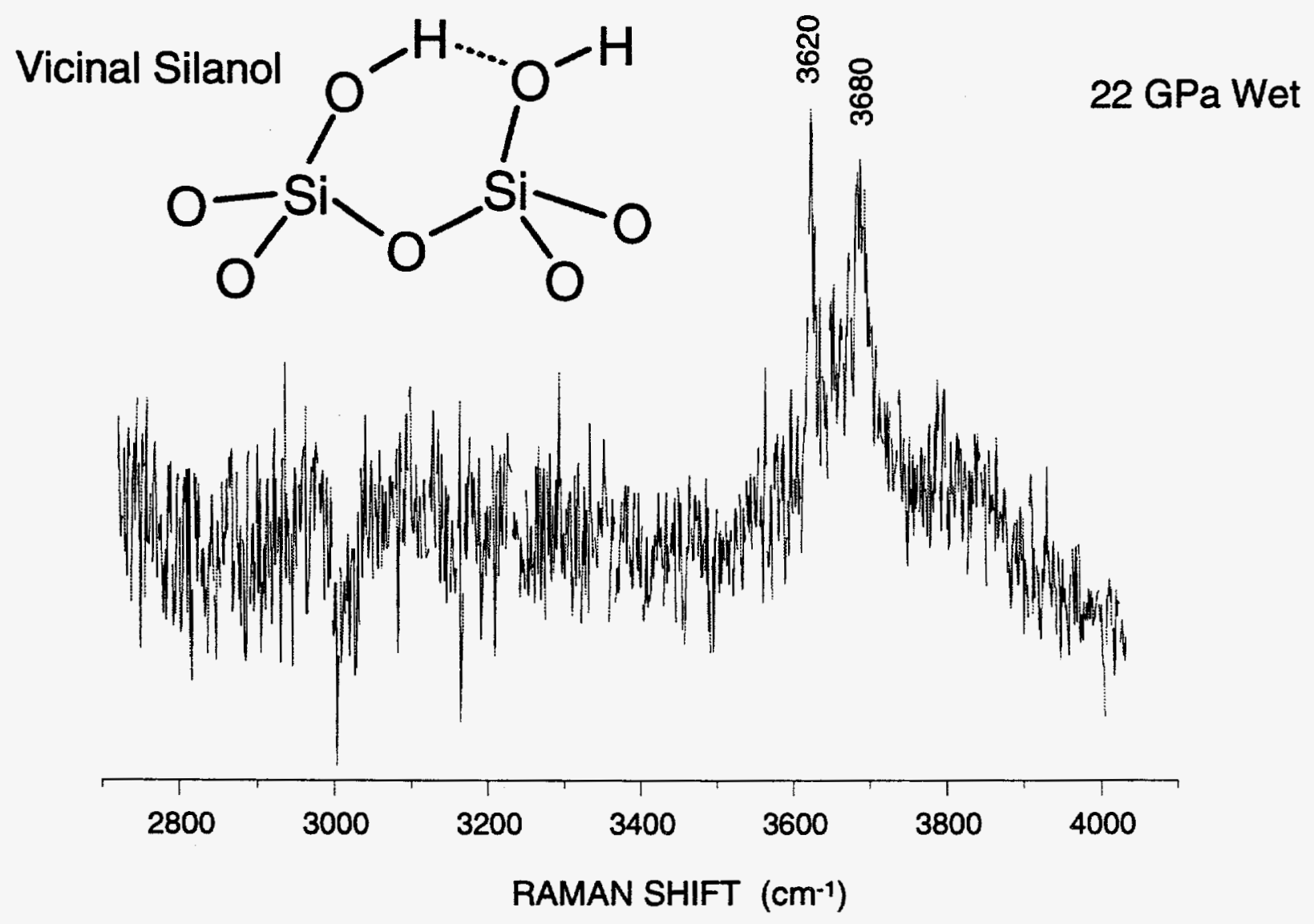

Figure 3. Laser Raman spectrum for material recovered from the high temperature $22 \mathrm{GPa}$ shock of water-saturated Coconino Sandstone. The presence of vicinal silanol groups is suggested by the bands in the $3600 \mathrm{~cm}^{-1}$ region. 


\section{REFERENCES}

Boslough, M. B., Cygan, R. T., and Kirkpatrick, R. J. (1993) ${ }^{29}$ Si NMR spectroscopy of naturally-shocked quartz from Meteor Crater, Arizona: Correlation to Kieffer's classification scheme. (abstract) Lunar and Planetary Science Conference, 24, 149-150.

Cygan, R. T., Boslough, M. B., and Kirkpatrick, R. J. (1994a) NMR spectroscopic examination of shocked sandstone from Meteor Crater, Arizona. In S. C. Schmidt, Ed., High Pressure Science and Technology - 1993, Elsevier, Amsterdam, in press.

Cygan, R. T., Boslough, M. B., and Kirkpatrick, R. J. (1994b) NMR spectroscopy of experimentally-shocked Coconino sandstone and the effect of pore water. (abstract) Lunar and Planetary Science Conference, 25, 309-310.

Kieffer, S. W. (1971) Shock metamorphism of the Coconino Sandstone at Meteor Crater, Arizona. Journal of Geophysical Research, 76, 54495473. 


\section{LIST OF PUBLISHED PAPERS}

Assink, R. A., Boslough, M. B., and Cygan, R. T. (1994) Power-law relaxation of spin-1/2 nuclei in solids. Journal of Magnetic Resonance, A106, 116118.

Assink, R. A., Boslough, M. B., and Cygan, R. T. (1993) Characterization of amorphous material in shocked quartz by NMR spectroscopy. In S. C. Schmidt, Ed., High Pressure Science and Technology - 1993, Elsevier, Amsterdam, in press.

Boslough, M. B., Cygan, R. T., and Kirkpatrick, R. J. (1992) NMR characterization and relaxation analysis of amorphous material in shocked quartz. (abstract) Transactions of the American Geophysical Union, 73, 594-595.

Boslough, M. B., Cygan, R. T., and Kirkpatrick, R. J. (1993) ${ }^{29}$ Si NMR spectroscopy of naturally-shocked quartz from Meteor Crater, Arizona: Correlation to Kieffer's classification scheme. (abstract) Lunar and Planetary Science Conference, 24, 149-150.

Boslough, M. B., Cygan, R. T., Assink, R. A., and Kirkpatrick, R. J. (1994) NMR characterization of shocked quartz. (abstract) Proceedings of NIRIM International Symposium on Advanced Materials ' 94 .

Boslough, M. B., Cygan, R. T., Assink, R. A., and Kirkpatrick, R. J. (1994) NMR characterization of shocked quartz. Proceedings of NIRIM International Symposium on Advanced Materials '94, in press.

Cygan, R. T., Boslough, M. B., and Kirkpatrick, R. J. (1994) NMR spectroscopic examination of shocked sandstone from Meteor Crater, Arizona. In S. C. Schmidt, Ed., High Pressure Science and Technology - 1993, Elsevier, Amsterdam, in press.

Cygan, R. T., Boslough, M. B., and Kirkpatrick, R. J. (1994) NMR spectroscopy of experimentally-shocked Coconino sandstone and the effect of pore water. (abstract) Lunar and Planetary Science Conference, 25, 309310. 


\title{
Power-Law Relaxation of Spin- $\frac{1}{2}$ Nuclei in Solids*
}

\author{
R. A. ASSINK, M. B. BOSLOUGH, AND R. T. CYGAN \\ Sandia National Laboralories, Albuquerque. New Mexico 87185
}

Received April 5, 1993: revised June 22, 1993

We are using ${ }^{29} \mathrm{Si}$ NMR spectroscopy to characterize the chemical structure of a variety of silicate materials $(1,2)$. Since these studies usually require the recording of quantitative spectra, a direct polarization experiment with magic angle spinning (MAS) is employed. We have found that many samples do not possess a well-defined $T_{1}$, but rather exhibit a power-law relationship between the magnetization intensity and pulse delay time. This behavior is the result of relaxation of spin- $\frac{1}{2}$ nuclei by paramagnetic impurities under MAS conditions ( 3 ). This Note describes the complications one must consider when spectra of spin- $\frac{1}{2}$ nuclei in solids are recorded, how the relaxation by paramagnetic impurities may be used to characterize the spatial structure of a material, and some proposals by which the very long recovery times of these materials can be circumvented.

Figure I shows the magnetization recovery for an $\alpha$-quartz powder from Alfa Products recorded at $4.7 \mathrm{~T}$ using a comb saturation sequence, direct polarization, and MAS at $4 \mathrm{kHz}$. The solid line is a theoretical fit assuming a 37 s exponential recovery of the magnetization. The fit is reasonable and considering the effor needed to acquire additional data ( 3600 scans recorded at $10 \mathrm{~s}$ and 360 scans recorded at $100 \mathrm{~s}$ ), one is templed to conclude that the $100 \mathrm{~s}$ pulse delay is adequate for a reasonably quantitative spectrum. This conclusion would lead to serious error.

Figure 2 shows the magnetization recovery for the same a-quarz sample for much longer delay times. The recovery is plotted on a log-log scale from which it is obvious that the magnetization follows power-law behavior over five decades of time. Calibration of the spectrometer with silicate samples having shorter relaxation times confirms that the magnetization is near equilibrium for the longest times recorded in Fig. 2. Spectra recorded at $100 \mathrm{~s}$ would have accounted for only $2 \%$ of the equilibrium magnetization and the relative intensities of a multicomponent spectrum could have suffered serious distortion.

When recording the spectra of samples which exhibit exponential recovery, one can predict the equilibrium magnetization on the basis of experiments employing delay times

- This work performed at Sandia National Luboratories, supporned by the U.S. Deparment of Energy under Contract DE-AC04-76DP00789. on the order of $T_{1}$. Note that there is no such analogy when the sample exhibits power-jaw behavior. The data for delay times ranging from 1 to $100,000 \mathrm{~s}$ give no indication of the equilibrium magnetization. For this reason, we routinely calibrate the response of the spectrometer so that if the spin density and mass of the sample are known, we can predict when the recorded magnetization is approaching equilibrium.

Power-law behavior of the magnetization recovery has been observed previously for paramagnetically doped solgel-derived silicate samples (3). Power-law behavior for spin1 nuclei is expected whenever the sample is undergoing MAS and its relaxation is dominated by randomly distributed paramagnetic impurities. Although the samples in this study were not intentionally doped, they contain low levels of paramagnetic impurities (4). The power-law exponent of 0.54 is reasonably close to the value of 0.50 predicted for a three-dimensional material.

Figure 3 shows the magnetization recovery of an a-quartz sample which has been subjected to a $22 \mathrm{GPa}$ shock wave (5). The recovery again displays power-law characteristics. However, the power-law exponent of the shocked sample is only 0.39 . Representative spectra for the unshocked and shocked quartz samples are shown in Fig. 4. The spectra for the unshocked sample have qualitatively similar features. independent of recovery time. The spectra for the shocked sample appear quite different for short and long recovery times. For short recovery times, the spectra of the shocked sample exhibit both broad and narrow components. The narrow component corresponds to the normal crystalline phase as observed for the unshocked sample, while the broad component corresponds to a disordered phase produced by the shock wave. For short recovery times, the broad component dominates, while for long recovery times, the narrow component dominates to the extent that the contribution of the broad component is not observed. These spectra illustrate the importance of recognizing the relaxation characteristics of a complex material. By analyzing the spectra of the shocked quartz, we are able to estimate the proportion of disordered to ordered phase and determine the fractal dimension of each phase ( 6 ). 


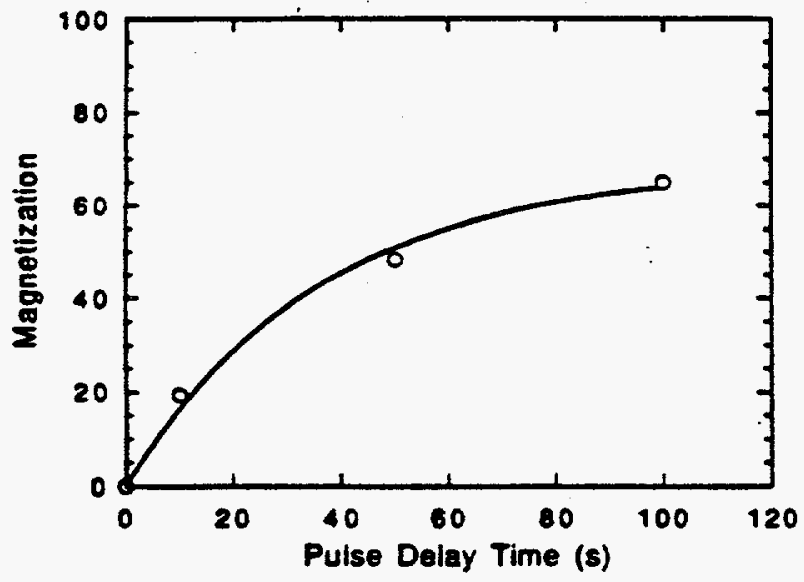

FIG. 1. The magnetization recovery of an a-quarz sample for times up to $100 \mathrm{~s}$. The solid line is a theoretical fit assuming a 37.2 s exponential recovery. $M=M_{0}\left[1-\exp \left(-1 / T_{1}\right)\right]$

The spectra for both the unshocked and the shocked samples take a very long time to accumulate. We have considered methods by which this time can be reduced. Figure 5 shows the magnetization recovery versus pulse delay time of unshocked quartz samples with and without MAS. The recovery curve for the sample without MAS was obtained by allowing the sample to polarize while static and then applying MAS during the observation period. By eliminating MAS, nuclear spin diffusion is again effective and the relaxation rate increases dramatically. The magnetization recovery of the static sample is described reasonably well by a spin-lattice relaxation time of $3800 \mathrm{~s}$. More importantly, the time to acquire a quantitatively correct spectrum is reduced an order of magnitude by application of this simple nonspin/spin sequence.

Figure 6 shows the relaxation time of the magnetization for the unshocked sample in zero field. These measurements

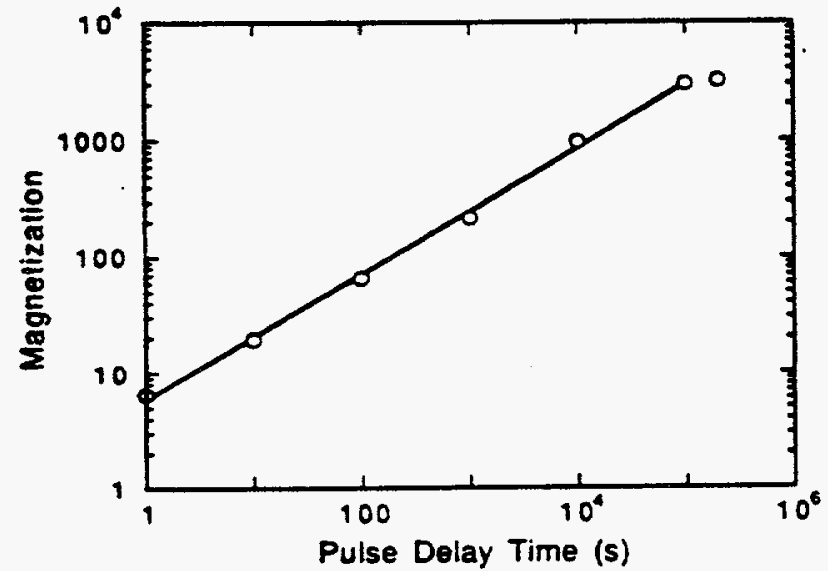

FIG. 2. The magnetization recovery of an a-quartz sample on a loglog scale. The recovery follows power-law behavior over five decades of time. $M=A t^{\circ} . a=0.54$.

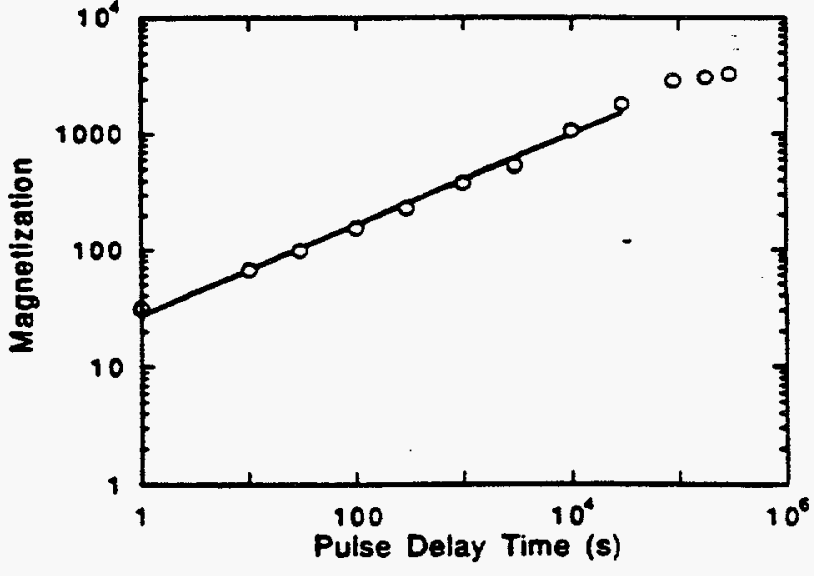

FIG. 3. The magnetization recovery of an a-quarz sample subjected $10222 \mathrm{GPa}$ shock wave. A power-law fit is shown, although the magnetuzation consists of components with differing relaxation behavior (ser Fig. 4 and texi). $M=A t^{\circ}, a=0.39$

were obtained by allowing the spins to polarize, removing the spins from the magnetic field for various periods of time, and then restoring the magnetic field and sampling their po-
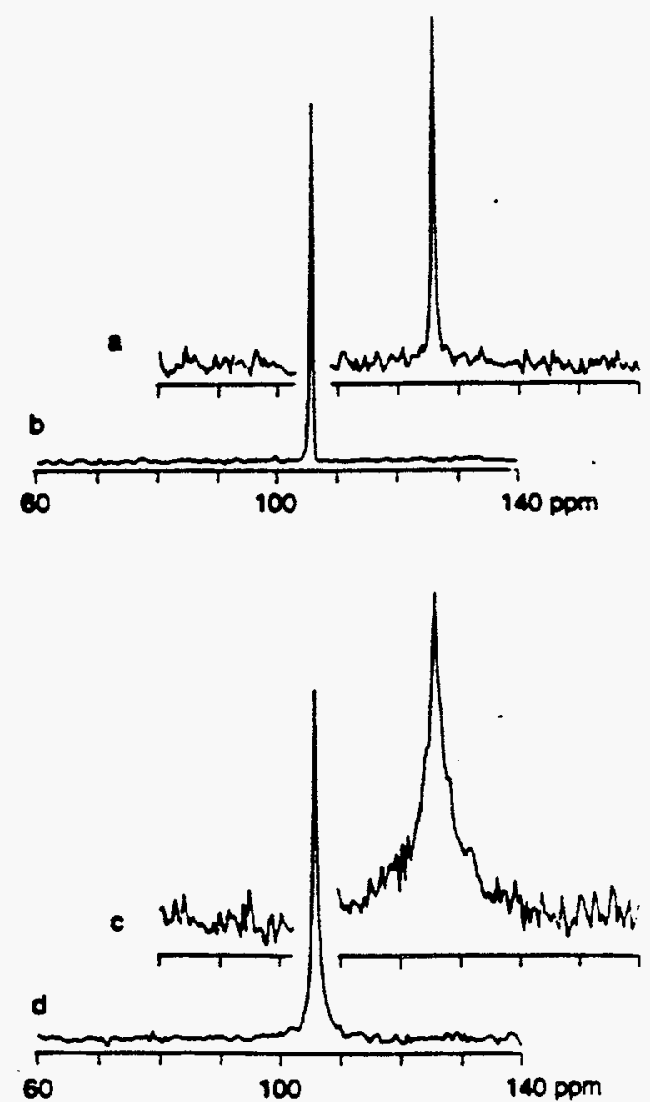

FIG. 4. Representative spectra of the unshocked a-quanz sample at (a) 10 s and (b) $100,000 \mathrm{~s}$ recovery times and of the shocked a-quarz sample at (c) 10 s and (d) 90,000 s recovery times. 
larization. This adiabatic demagnetization/magnetization has been described previously (7). The relaxation time in zero field is approximately $130 \mathrm{~s}$. This result suggests that one could simultaneously polarize several samples in a region of the magnet adjoining the probe or in a nearby magnet and then transport them to the probe for observation under MAS conditions.

MAS can quench the spin diffusion of dilute spin- $\frac{1}{2}$ nuclei in solids, thereby increasing the relaxation time and changing the functional form of the magnetization recovery. Recog. nition of this phenomenon is important when recording quantitative spectra and also suggests operational procedures by which the long times to record spectra of these materials may be reduced.

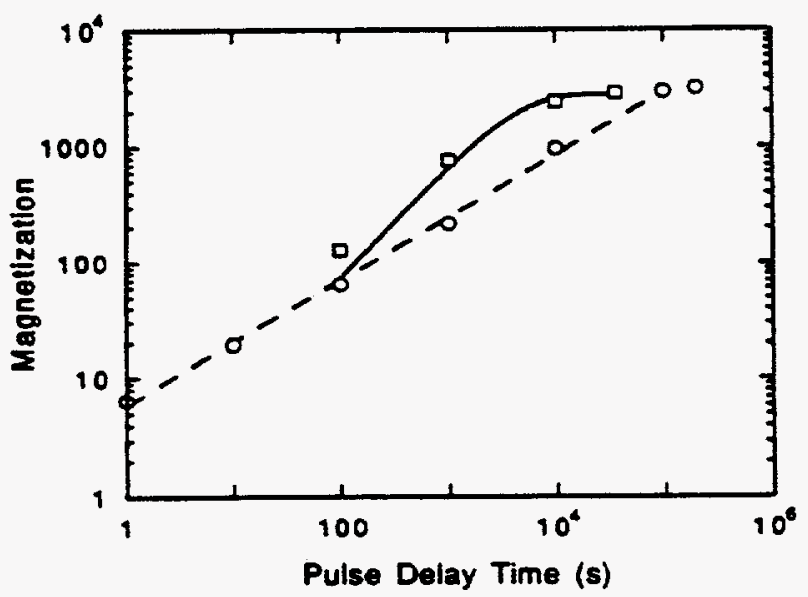

FIG. 5 . The magnetization recovery of a static $(-) \alpha$-quartz sample compared to that of the same sample undergoing MAS (---). The recoveries were fitted by exponential and power-law functions respectively. $M=M_{\mathrm{d}}[1$ $\left.-\exp \left(-t / T_{1}\right)\right] . T_{1}=3800 \mathrm{~s}$.

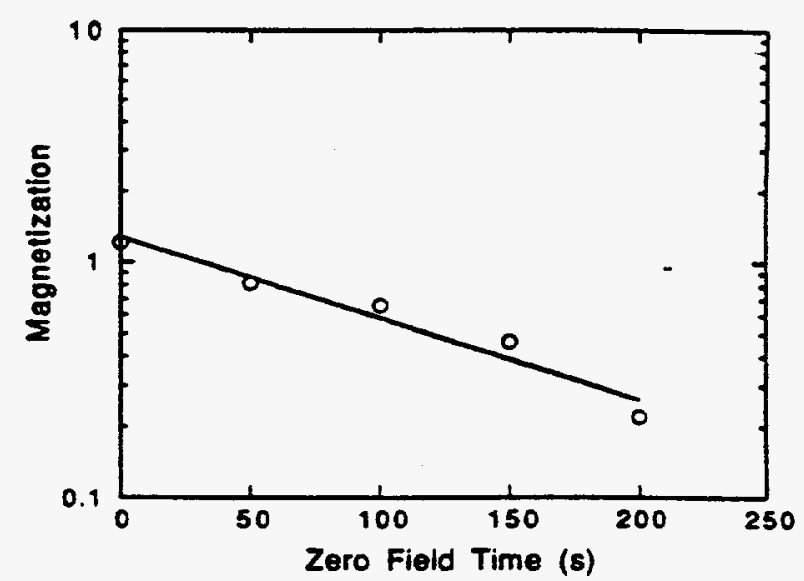

FIG. 6. The zero-field magnetization decay of an $\alpha$-quartz sample. $M$ $=M_{\alpha x p}\left(-t / T_{1}\right) \cdot T_{1}=380 \mathrm{~s}$

\section{REFERENCES}

1. P. J. Davis, C. J. Brinker, D. M. Smith, and R. A. Assink, J. Non-Cryst. Solids 142, 197 (1992)

2. T. A. Ulbari, G. Beaucage, D. W. Schaefer, B. J. Oivier, and R. A. Assink, Mat. Res. Soc. Symp. Proc. 274, 85 (1992).

3. F. Devreux, J. P. Boilot, F. Chaput, and B. Sapoval, Phys. Rev. Lett. 65,614 (1990).

4. E. L. Venturini, persond communication.

5. R. T. Cygan, M. B. Boslough, and R. J. Kirkpatrick, Proc. Lunar Planet. Sci. 22, 127 (1992).

6. A. A. Assink. R. T. Cygan, and M. B. Bosiough, The 34th Experimental NMR Conference, St. Louis. Missouri, 1993.

7. A. Abragam, "The Principles of Nuclear Magnetism," p. 144, Oxford Univ. Press, London, 1961. 


\title{
Characterization of Amorphous Material in Shocked Quartz by NMR Spectroscopy*
}

\author{
R. A. Assink, M. B. Boslough and R. T. Cygan \\ Sandia National Laboratories \\ Albuquerque, NM 87185
}

\begin{abstract}
Nuclear magnetic resonance (NMR) analysis of the recovered products from a series of controlled explosive shock-loading experiments on quanz powders was performed to investigate shock-induced amorphization processes. Silicon-29 NMR spectroscopy is an excellent probe of the local bonding environment of silicon in minerals and is capable of detecting and characterizing amorphous and disordered components. NMR spectra obtained for the recovered material exhibit a narrow resonance associated with the shocked crystalline material, and a broad component consistent with an amorphous phase despite the absence of evidence for glass from optical microscopy. The NMR measurements were performed over a range of recycle times from 1 to $3 \times 10^{5} \mathrm{~s}$. The results demonstrate that the magnetization in both the crystalline and amorphous material follows power-law behavior as a function of recycle time. The amorphous component dominates the spectra for short NMR recycle times due to its shorter relaxation time relative to the crystalline material. Fractal analysis of the power-law relations suggests a fractal dimension of 2 for the amorphous phase and 3 for the crystalline phase.
\end{abstract}

\section{INTRODUCTION}

Identification of shocked minerals and determination of their degree of shock metamorphism has become an increasingly important problem in earth and planetary science as the relative importance of impact processes has been recognized. Diagnostic methods for examining shock features in minerals have traditionally relied on qualitative examination of microstructures by optical and electron microscopy. Silicon-29 NMR spectroscopy offeres the potential for quantitatively assessing the degree of shock metamorphism in silicates by probing the local bonding environment of silicon. This paper describes its application to structural studies of amorphous material in shocked quartz powder.

\section{EXPERIMENTAL}

The shock recovery experiments using quartz powder samples were carried out in the same manner as those for the study of Cygan et al. [1]. The experiment made use of the Sandia "Momma Bear" explosive loading fixture to achieve a wellcharacterized shock state. These recovery fixtures allow samples to be shocked in a controlled, reproducible manner. Shock pressure and temperature histories were determined numerically by two-dimensional computer simulations [2]. The peak shock pressure was 22 $\mathrm{GPa}$. The starting material was synthetic $\alpha$-quartz sieved to a mean grain size of less than $38 \mathrm{\mu m}$ $(-325$ mesh). The quartz was annealed at $900 \mathrm{C}$ for $20 \mathrm{hr}$ to minimize the initial defect densities that had previously broadened the (101) X-ray diffraction peak [1].

The NMR spectra were recorded on a Chemagnetics spectrometer at a field strength of 4.7 T. Direct polarization, a comb saturation sequence and magic angle spinning (MAS) at 4 $\mathrm{kHz}$ were employed. The number of scans ranged from 36,000 for shor pulse delays to 1 for long pulse delays. 


\section{RESULTS AND DISCUSSION}

Figure 1 shows the magnetization recovery for. an $\alpha$-quartz sample which has not been shocked. The recovery is plotted on a log-log scale from which it is obvious that the magnetization follows power-law behavior over 5 decades of time. Calibration of the spectrometer with silicate samples having shorter relaxation times confirms that the magnetization is near equilibrium for the longest times recorded in Figure 1.

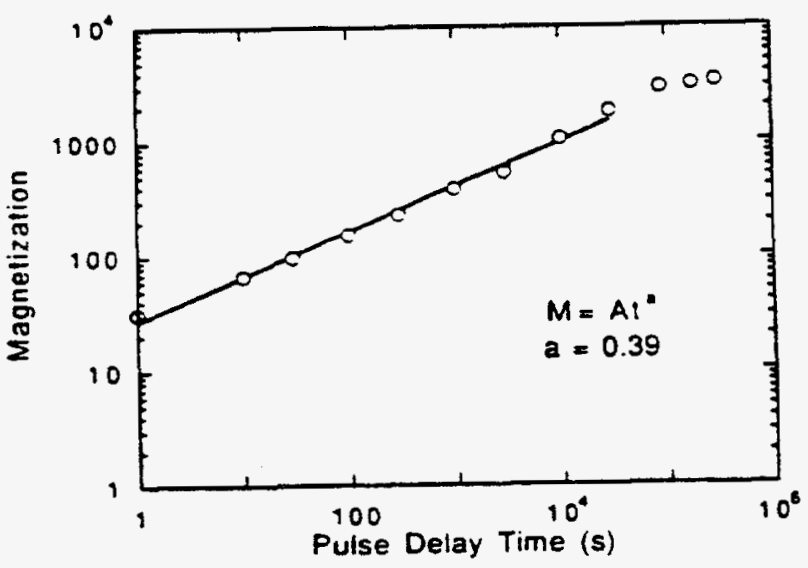

Figure 1. The magnetization recovery of an $\alpha$ quartz sampie on a $\log -\log$ scale. The recovery follows power-law behavior over 5 decades of time.
Figure 2 shows the magnetization recovery of an $\alpha$-quartz sample which has been subjected to a $22 \mathrm{GPa}$ shock wave. The recovery again displays power-law characteristics. However, the powerlaw exponent of the shocked sample is only 0.39 .

Representative spectra for the unshocked and shocked quartz samples are shown in Figure 3. The spectra for the unshocked sample have qualitatively similar features, independent of recovery time. The spectra for the shocked sample, however, appear quite different for short and long recovery times. For short recovery

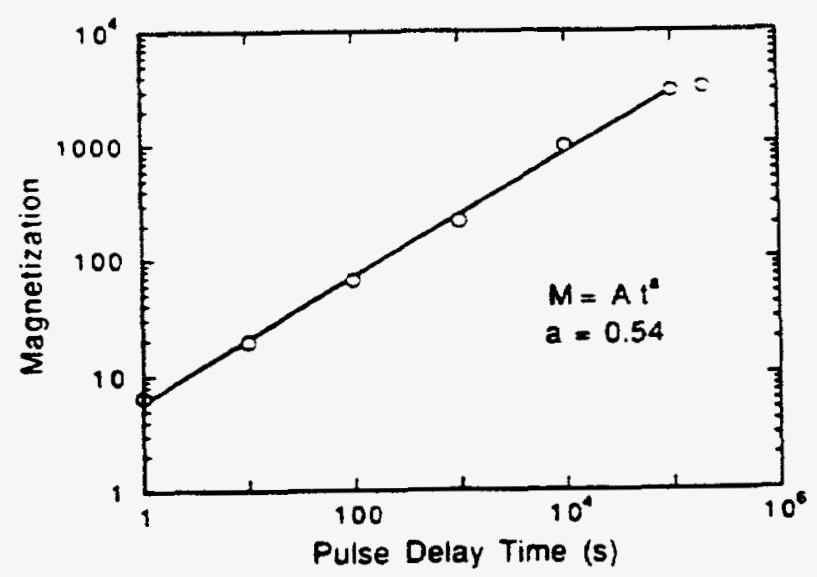

Figure 2. The magnetization recovery of an $\alpha$ quartz sample subjected to a $22 \mathrm{GPa}$ shock wave. $A$ power-law fit is shown, although the magnetization consists of components with differing relaxation behavior (see Figure 4 and text).

times, the spectra of the shocked sample exhibit both broad and narrow components. The nartow component corresponds to the normal ordered phase as observed for the unshocked sample, while the broad component corresponds to a disordered phase produced by the shock wave. For short recovery times the broad component dominates, while for long recovery times the narrow component dominates to the extent that the contribution of the broad component is not observed. These spectra illustrate the importance of recognizing the relaxation characteristics of a complex material. 

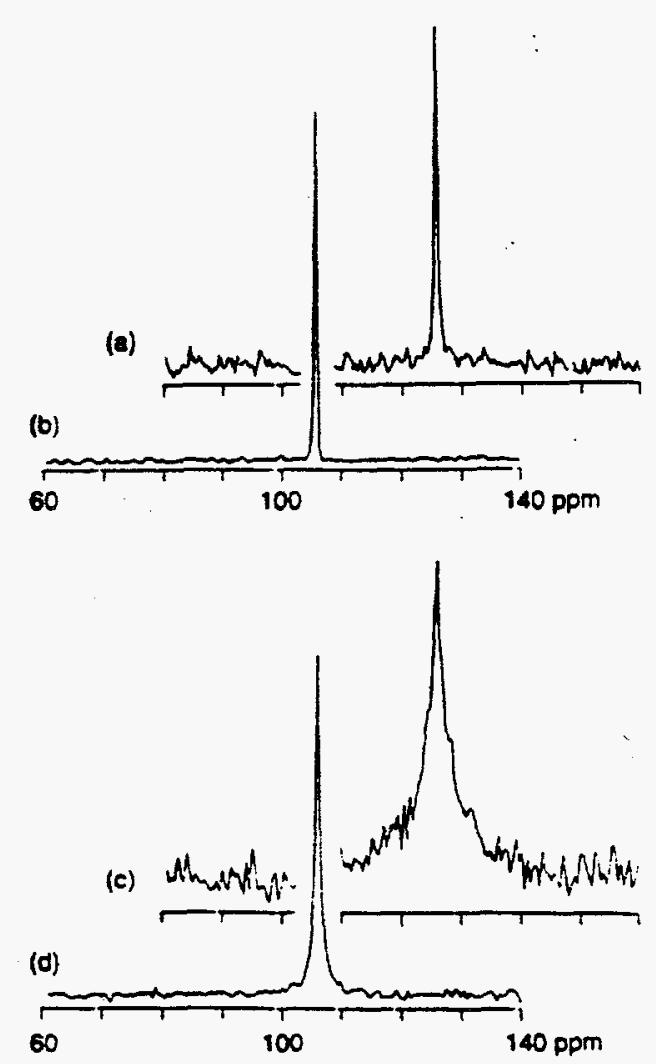

Figure 3. Representative spectra of the unshocked $\alpha$-quartz sample at (a) $10 \mathrm{~s}$ and (b) $100,000 \mathrm{~s}$ pulse delay times and of the shocked $\alpha$ quariz sample at (c) $10 \mathrm{~s}$ and (d) $90,000 \mathrm{~s}$ puise delay times.

By analyzing the spectra of the shocked quartz, we are able to estimate the ratio of disordered to ordered phase and determine the fractal dimension of each phase. The spectra of the shocked quartz were numerically fit with two components: a narrow Lorentzian component corresponding to an ordered phase and a broad Gaussian component corresponding to a disordered phase. A Lorentzian lineshape provides the best fit for the entire spectrum of the unshocked material as well as the best fit for the narrow component of the shocked material. A Gaussian lineshape provides the best fit for the broad component of the shocked material. Figure 4 shows the relative intensity of each component as a function of pulse delay time.

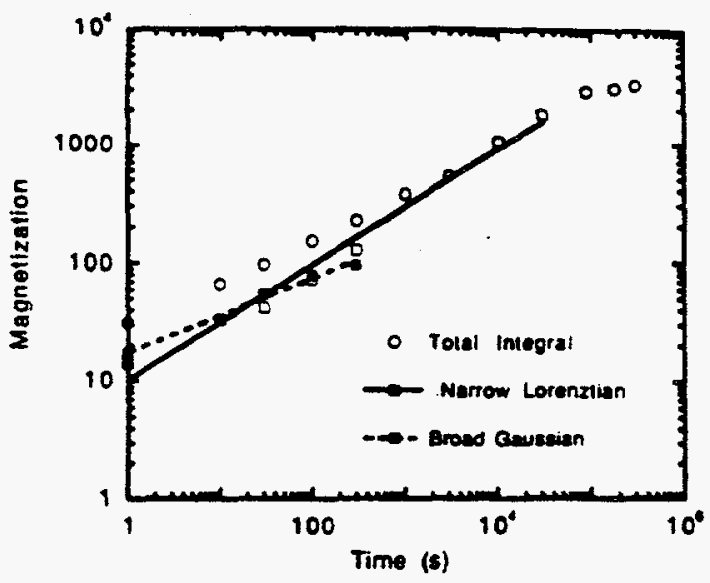

Figure 4. The magnetization recovery of an $\alpha$ quartz sample subjected to a $22 \mathrm{GPa}$ shock wave. Each spectrum has been deconvoluted into a narrow Lorenztian component corresponding to the ordered phase and into a broad Gaussian component corresponding to the disordered phase.

The broad Gaussian component has a powerlaw exponent of 0.32 which corresponds to a fractal dimension of two, while the narrow Lorentzian component has a power-law exponent of 0.49 which corresponds to a fractal dimension of three.

The equilibrium intensities of each component are proportional to the amounts of material in each phase. For times of $10,000 \mathrm{~s}$ and above,-the broad resonance was a fairly minor component of the total signal and could be ignored. Thus, a reasonable estimation can be made of the equilibrium signal corresponding to the ordered phase. The intensity of the equilibrium signal corresponding to the disordered phase could not be quantitatively determined, however, because the spectra were difficult to fit in the 1000 to $3,000 \mathrm{~s}$ time regime. We estimate that the disordered phase accounts for less than $10 \%$ of the shocked quartz. 


\section{CONCLUSIONS}

The silicon-29 NMR spectra of shocked quartz consist of two components corresponding to ordered and disordered phases. The spin-lattice relaxation of each phase exhibited power-law behavior which suggests that the disordered phase is two dimensional while the ordered phase is three dimensional. The disordered phase is estimated to account for less than $10 \%$ of the material.

\section{ACKNOWLEDGMENTS}

This work was performed at Sandia National Laboratories, supported by the U. S. Department of Energy under contract number DE-AC0476DP00789.

\section{REFERENCES}

[1] R. T. Cygan, M. B. Boslough, and R. J. Kirkpatrick, "NMR Spectroscopy of Experimentally Shocked Quartz: Shock Wave Barometry," in Proceedings of Lunar and Planetary Science 20, 1990, pp. 451-57.

[2] R. A. Graham and D. M. Webb, in Shock Waves in Condensed Matter, Y. M. Gupta, ed., New York, Plenum, 1985, pp. 831-36.

[3] F. Devreux, J. P. Boilot, F. Chaput, and B. Sapoval, Physical Review Letters 65, 614 (1990).

[4] E:L. Venturini, personal communication. 
NMR Characterization and Rejaxation Analysis of Amorphous Material in Shocked Quartz

M B Boslough (Experimental Impact Physics Dept. 1433, Sandia

National Laboratories, Albuquerque, NM 87185; 505-845-8851)

R T Cygan (Geochemistry Dept. 6118, Sandia National Laboratories, Albuquerque, NM 87185; 505-844-7216)

R A Assink (Properties of Organic Materials Dept. 1812, Sandia

National Laboratories, Albuquerque, NM 87123; 505-844-6372)

Amorphization can occur as a natural process when certain minerals undergo shock loading as a result of meteorite impacts. We have performed a series of controlled explosive shock-loading experiments on quartz powders. Subsequent analysis of the recovered shocked material by ${ }^{29} \mathrm{Si}$ NMR spectroscopy provides a new method for quantitative characterization of the amorphous/disordered silica component. In addition to a very narrow resonance associated with the shocked crystalline material, the spectra exhibit a broad component consistent with an amorphous phase, despite the absence of optical microscopic evidence for glass. The relative intensity of the broad resonance exhibits a strong correlation with known peak shock pressure, and can be used as a "shock barometer".

New NMR measurements over a wide range of recycle times (from 1 to $3 \times 10^{5}$ seconds) demonstrate that magnetization in both the amorphous and crystalline components follow power-law behavior as a function of recycle time. This observation is consistent with the relaxation of nuclear spins by paramagnetic impurities. The amorphous component has a shorter relaxation time than the crystalline phase, and therefore dominates the spectra for short NMR recycle times. It has previously been shown that a fractal dimension can be extracted from the power-law exponent associated with each phase. The fractal dimension determined in this way for the amorphous phase is about 2 , as opposed to 3 for the crystalline phase.

* Supported by the Department of Energy under contract DE-AC0476DP00789, with partial funding from the Defense Nuclear Agency. 
¿SI NMR SPECTROSCOPY OF NATURALLY-SHOCKED QUARTZ FROM METEOR CRATER, ARIZONA: CORRELATION TO KIEFFER'S CLASSIFICATION SCHEME M. B. Boslough', R T. CYgan', and R. J. Kirkpatrick', 'Sandia National Labs, Albuquerque, NM 87185 and 'U. of Illinois, Urbana, II 61801.

We have applied solid state ${ }^{2} \mathrm{Si}$ nuclear magnetic resonance (NMR) spectroscopy to five naturally-shocked Coconino Sandstone samples from Meteor Crater, Arizona, with the goal of examining possible correlations between NMR spectral characteristics and shock level. This work follows our observation of a strong correlation between the width of a ${ }^{20} \mathrm{Si}$ resonance and peak shock pressure for experimentally shocked quartz powders [1,2]. The peak width increase is due to the shock-induced formation of amorphous silica, which increases as a function of shock pressure over the range that we studied (7.5 to $22 \mathrm{GPa}$ ). The Coconino Sandstone spectra are in excellent agreement with the classification scheme of Kieffer [3] in terms of presence and approximate abundances of quartz, coesite, stishovite, and glass. We also observe a new resonance in two moderately shocked samples that we have tentatively identified with silicon in tetrahedra with one hydroxyl group in a densified form of amorphous silica.

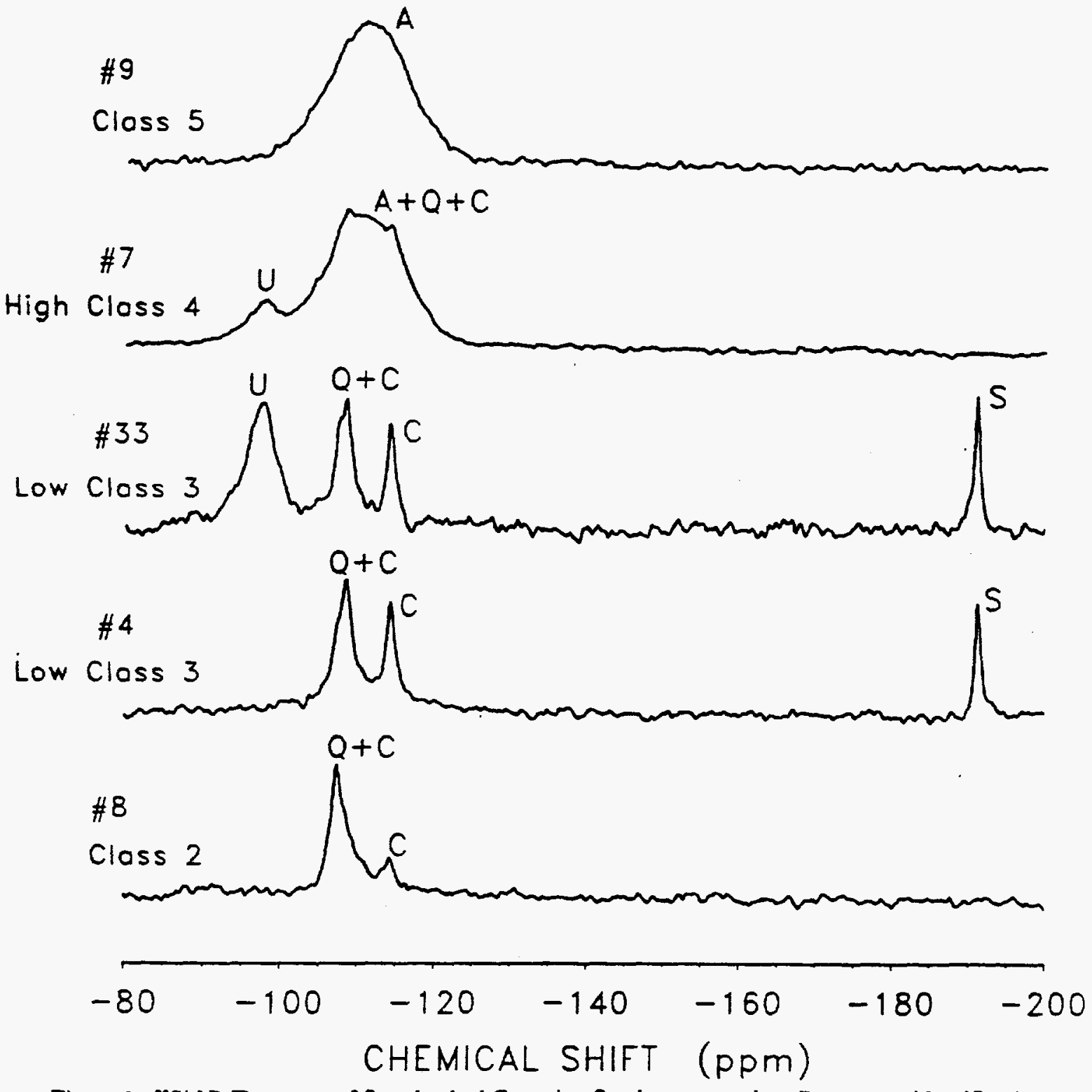

Figure 1. ${ }^{29} \mathrm{Si}$ NMR spectra of five shocked Coconino Sandstone samples. Resonance identifications are (Q) quarz, (C) coesite, (S) stishovite, (A) Q sites in amorphous silica, and (U) unknown site tentatively identified as $Q^{3}$ (one $\mathrm{OH}$ ) Si sites in a densified form of hydroxylated amorphous silica. 
We have previously suggested that NMR spectra be used as a "shock barometer", or at least as an identification technique for shocked quartz. However, our measurements to date have been limited to laboratoryshocked samples. Because the duration of shock loading can be many orders of magnitude longer for large impacts, major differences are to be expected. To address these possible differences, we hove now turned our attention to naturally-shocked samples. Application of solid state NMR spectroscopy to auch samples has been limited. Smith and Blackwell [4] measured spectra of coesite and stishovite taken from shocked Coconino Sandstone as part of a comparative study of silica polymorphs. Yang et al. [5] showed that this technique is very sensitive to high-pressure silica phases from whole rock samples of shocked Coconino Sandrone, and is capable of yielding accurate coesite/stishovite ratios. Mchone a al. [6] applied the technique to samples collected from the $\mathrm{K} / \mathrm{T}$ boundary and reported the detection of trace amounts of stishovite, although this interpretation has been disputed [7].

In the present work, we obtained spectra for five samples of Coconino Sandstone representing shock classes 2-5 (Fig. 1). The following is a preliminary summary of our observations. Class 2 (sample \#8): mostly quarz, small amounts of coesite and possibly amorphous silica, no stishovite. Class 3 (sample 44): mostly quarz, more coesite than sample \#8, some amorphous silica, and stishovite. Class 3 (sample \#33): same as sample \#4, but with an additional peak, possibly due to $Q^{3}$ (one $O H$ ) Si sites in a dense form of hydroxylated amorphous silica. Cless 4 (sample \#7): mostly amorphous silica, with some quartz and coesite, no stishovite, contains a less intense peak possibly associated with the same $Q^{2}$ site as in sample \#33. Class 5 (sample "19): almost entirely amorphous silica, no stishovite. Of particular note are the surprisingly strong stishovite resonances in the Class 3 samples; the stishovite peak observed by Yang $e$ al. [5] is significantly weaker. We also observed a more intense X-ray line $\left(2 \theta=30.2^{\circ}\right)$ for stishovite, implying there is more of this phase in our samples. The only samples for which we observe stishovite are those previously identified as Class 3.

The presence of an unidentified peak with a chemical shift of about $-98 \mathrm{ppm}$ in two of our samples (\#33 and :7) is especially noteworthy. There is no X-ray diffraction evidence for significant amounts of any crystalline material other than the three silica polymorphs. There are several lines of evidence that this resonance corresponds Si in tetrahedra with one hydroxyl group in a dense form of hydroxylated amorphous silica: 1) The large intensity implies that, unless it is a major phase, it has a very shor relaxation time $\left(T_{1}\right)$, consistent with previous observations for shock-produced amorphous siliea. 2) The shif to higher frequency (smaller negative ppm value) is consistent with a denser phase than a similar phase formed at one atmosphere for a given $\mathrm{Si}$ coordination. A dense amorphous phase has been identified in NMR spectra obtained by Nellis et al. [8] from crystalline quarz shocked to $33 \mathrm{GPa}$, with a resonance centered at about $-106 \mathrm{ppm}$, an upfield shif of about 6 ppm from -112 ppm for normal-density silica glass [9]. The resonance for $Q^{3}$ (one $O H$ ) Si sites in a normaldensity gel is at about $-102 \mathrm{ppm}$ [10]. Our observed peak position of about -98 would be consistent with densification by roughly the same amount as the amorphous silica associated with shocked quarz. 3) The peak is broad, indicating a wide range of Si-O-Si bond angles typical of amorphous material, and is inconsistent with $\mathrm{Si}$ in clay or feldspar. 4) The target Coconino Sandstone was wet, and there is TEM evidence for vesicular "froth" (consisting of amorphous material produced by steam separation) in Class 3 samples [11]. 5) We have observed in a previous NMR study of clinoptilolite that shock loading can generate hydroxyl groups [12].

Further work is required to confirm the identification of the unknown phase, and to answer other questions. NMR proton cross-polarization techniques can be used to enhance Si resonances near protons, as would be the case for this phase. NMR relaxation studies can provide characteristic fractal dimensions as has been done for amorphous material in experimentally-shocked quartz [13]. We are also in the process of obtaining NMR spectra for other naturally shocked samples, in particular for quarz from the $\mathrm{K} / \mathrm{T}$ boundary, that may have seen a radically different loading and unloading history than the Meteor Crater samples.

References: [1] Cygan et al. (1990) In Proc. Lunar Planet Sci. Conf. 20th, 451-457. [2] Cygan et al. (1992) In Proc. Lunar Planet Sci. Conf. 22nd, 127-136. [3] Kieffer (1971) J. Geophys. Res. 76, 5449-5473. [4] Smith and Blackwell (1984) Nature 303, 223-225. [5] Yang et al. (1986) Meteoritics 21, 117-124. [6] McHone a al. (1989) Science 243, 1182-1184. [7] Izett (1990) GSA Special Paper 249. [8] Nellis et al. (1992) EOS 73, No. 43, 594. [9] Oestrike et al. (1987) Geochim. Cosmochim. Acta 51, 2199-2209. [10] Phieiderer el al. (1990) J. Phys. Chem. 94, 4189-4194. [11] Kieffer et al. (1976) Contrib. Mineral Petrol. 59, 41-93. [12] Cygan et al. (1992) EOS 73, No. 14, 360. [13] Boslough et al. (1992) EOS 73, No. 43, 594.

Acknowledgments: S. Kjeffer kindly provided us with well-documented samples from her previous work. G. Turner obtained the NMR spectra. This work was funded by NASA's PMG program. 
Abstract for invited presentation at NIRIM Symposium on Advanced Materials, National Institute for Research in Inorganic Materials,

Tsukuba, Japan, March 14-17, 1994.

\title{
NMR Characterization of Shocked Quartz
}

\author{
M B Boslough, R T Cygan, R A Assink, and R.J. Kirkpatrick* \\ Sandia National Laboratories, Albuquerque, NM 87185 USA.
}

We have characterized experimentally and naturally-shocked quartz (both synthetic and natural samples) by solid state NMR spectroscopy. This method provides a means for quantitative characterization of the amorphous/disordered silica component. NMR spectra demonstrate that magnetization in both the amorphous and crystalline components follows power-law behavior as a function of recycle time. This observation is consistent with the relaxation of nuclear spins by paramagnetic impurities. A fractal dimension can be extracted from the power-law exponent associated with each phase. In addition, NMR spectra have led to our discovery of a new amorphous hydroxylated silica phase in naturally shocked sandstone from Meteor Crater, Arizona.

This work supported by the Department of Energy under contract DE-AC04-94AL85000, with partial funding from NASA.

*University of Illinois, Urbana, Il 61801 USA 


\title{
NMR Characterization of Shocked Quartz
}

\author{
MB Boslough', R T Cygan', R A Assink', and R.J. Kirkpatrick ${ }^{2}$ \\ Sandia National Laboratories, AJbuquerque, NM 87185 USA. \\ ${ }^{2}$ University of Dlinois, Urbana, II 61801 USA
}

\begin{abstract}
We have characterized experimentally and naturally-shocked quartz (both synthetic and natural samples) by solid state nuclear magnetic resonance (NMR) spectroscopy. Relaxation analysis of experimentally-shocked samples provides a means for quantitative characterization of the amorphous/disordered silica component NMR spectra demonstrate that magnetization in both the amorphous and crystalline components follows power-law behavior as a function of recycle time. This observation is consistent with the relaxation of nuclear spins by paramagnetic impurities. A fractal dimension can be extracted from the power-law exponent associated with each phase, and telative abundances can be extracted from integrated intensities of deconvolved peaks. NMR spectroscopy of naturally-shocked sandstone from Meteor Crater, Arizona (USA) led to the discovery of a new amosphous hydroxylated silica phase. Solid state NMR spectra of both experimentally and naturallyshocked guarz were unexpectedly rich in microstructural information, especially when combined with relaxation analysis and cross-polarization studies. We suggest solid state NMR as a potentially useful tool for examining shock-induced microstructural changes in other inorganic compounds, with possible implications for shock processing of structural ceramics.
\end{abstract}

\section{DTRODUCTION}

Identification of shocked minerals and determination of their degree of shock metamorphism has become an increasingly important problem in earth and planetary science as the relative imporance of hypervelocity impact processes has been recognized. Diagnostic methods for examining shock features in minerals have traditionally relied on qualitative examination of mictostructures by optical and electron microscopy. Silicon-29 NMR spectroscopy offers the potential for quantitatively assessing the degree of shock metamorphism in silicates by probing the local bonding environment of silicon. We have performed NMR analysis of both laboratory-shocked synthetic quartz powders, and of naturally-shocked quartz from Meteor Crater, Arizona, USA.

NMR analysis of the recovered products from controlled explosive shock-loading experiments was performed to investigate shock-induced amorphization processes. Si-29 NMR spectroscopy is an excellent probe of the local bonding environment of silicon in minerals and is capable of detecting and chasacterizing amorphous and disordered components. NMR spectra obtained for the recovered materials exhibit a narrow resonance associated with the shocked crystalline material, and a broad component consistent with an amorphous phase, despite the absence of evidence for glass from optical microscopy. The NMR measurements were performed over a range of recycle times from I second to 83 hours.

We have also collected spectra from five naturally-shocked Coconino Sandstone samples from Meteor Crater, with the goal of examining possible correlations between NMR spectral characteristics and shock level. We had previously found a strong correlation between the width of the Si-29 resonance and peak shock pressure for experimentally-shocked quarz, due to the shock-induced formation of amorphous silica, which increases as a function of shock pressure between 7.5 and 22 GPa [1,2]. We had suggested that NMR spectra could be used as a "shock barometer", or at least as a screening tool and sensitive method for identifying shocked quariz. However, because the duration of shock loading can be many orders of magnitude longer for natural impacts than for laboratory experiments, we examined the naturally-shocked specimens as well. 


\section{EXPERMMENTAL}

The shock recovery experiments using quart powder samples were carried out in the same manner as those for the study of Cygan et al. [1]. The experiment made use of the Sandia National Labonatories "Momma Bear" explosive loading fixture to achieve a well-characterized shock state. These recovery fixtures allow samples to be shocked in a controlled, reproducible manner. Shock pressure and temperature histories were determined numerically by two-dimensional computer simulations [3]. The peak shock pressure was $22 \mathrm{GPa}$. The starting material was synthetic $\alpha$-quartz sieved to a mean grain size of less than $38 \mu \mathrm{m}$ (-325 mesh). The quartz was annealed at $900^{\circ} \mathrm{C}$ for 20 hours to minimize the initial defect densities that initially braadened the (101) X-ray diffrection peak [1].

The NMR spectra of the experimentally-shocked samples were recorded on a Chemagnetics spectrometer, which detects radio-frequency re-emissions from active Si-29 nuclei that have been excited to a high-energy stake while the sample is immersed in a magnetic feld of $4.7 \mathrm{~T}$. Direct polarization, a comb saturation sequence, and magic angle spinning (MAS) at $4 \mathrm{kHz}$ were employed to provide spectra with significantly reduced dipolar intenctions and improved signal-to-noise ratio. The number of scans ranged from 36,000 for short pulse delays to 1 for long pulse delays.

The five samples of shocked Coconino Sandstone were obtained from Meteor Crater to represent the range of shock pressures associated with the impact. The samples are identical to those first examined by Kieffer using X-ray diffraction and optical microscopy [4]. The NMR spectra were obtained at a frequency of $71.5 \mathrm{MHz}$ with an applied magnetic feld of $8.45 \mathrm{~T}$. The MAS frequencies were typically at $3.5 \mathrm{kHz}$, and the pulse recycle time was $30 \mathrm{~s}$. Approximately 200 to $300 \mathrm{mg}$ of sample powder was used for each NMR analysis.

\section{RESULTS}

\section{Experimentally-Shocked Synthetic Ouarz:}

Representative spectra collected at two widely different pulse delay times are shown in Figure 1 for the unshocked and shocked synthetic quartz samples. Resonance freguencies are provided in terms of chemical shift (ppm relative to an external standard) and are related to the local bonding environment of silicon-29 nuclei and to the Si-O-Si bond angle distribution. The two spectra of the unshocked sample have qualitatively similar features, independent of recovery time. The spectra for the shocked sample, however, appear quite different for short and long recovery times. For short recovery times, the spectra of the shocked sample exhibit both broad and narrow components. The narrow component corresponds to the normal ordered phase and is similar to that observed for the unshocked sample, while the broad component corresponds to a disordered phase produced by the shock wave. For shor recovery times the narrow component dominates to the extent that the contribution of the broad component is not observed. These spectra illustrate the importance of recognizing the relaxation characteristics of complex material.

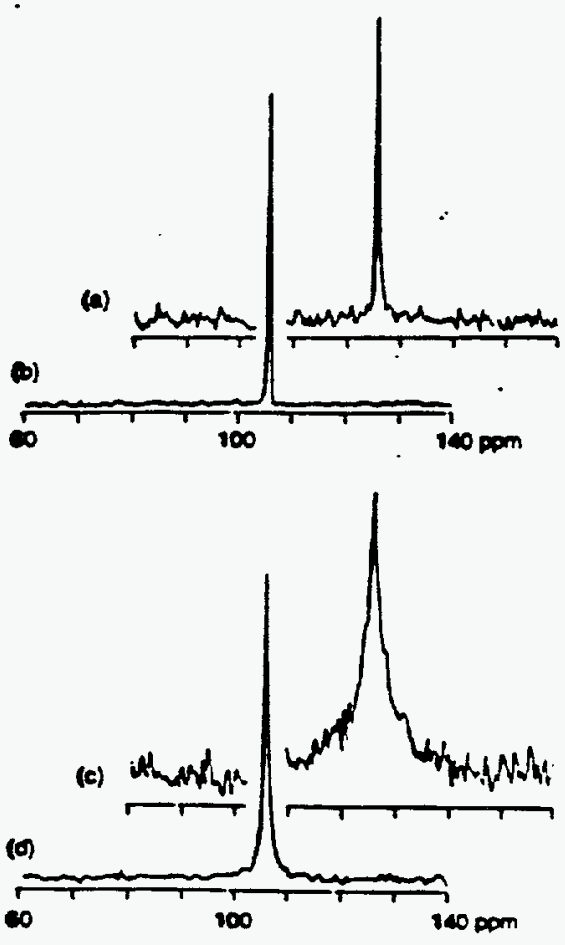

Figure 1. Spectra of unshocked $\alpha$-quarz at (a) $10 \mathrm{~s}$ and $100,000 \mathrm{~s}$ and of shocked $\alpha$-quarz at (c) $10 \mathrm{~s}$ and (d) $90,000 \mathrm{~s}$ delay time. 


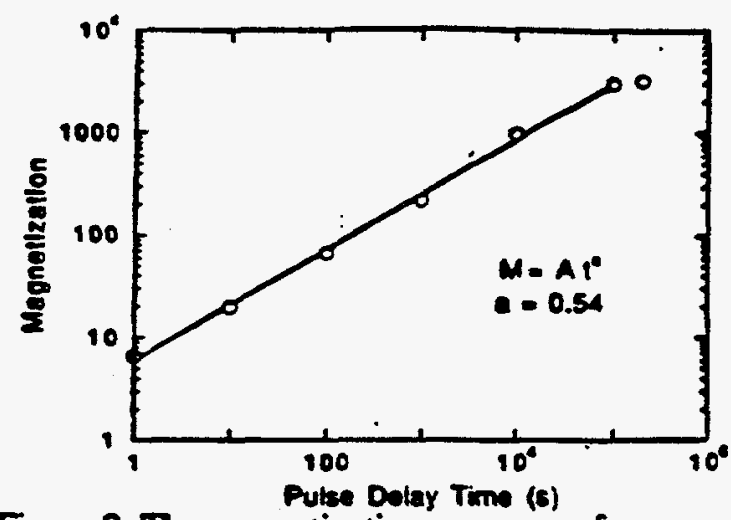

Figure 2. The magnetization recovery of an $\alpha$ quarz sample on a log-log scale, which follows power-law behavior over 5 decades of time.

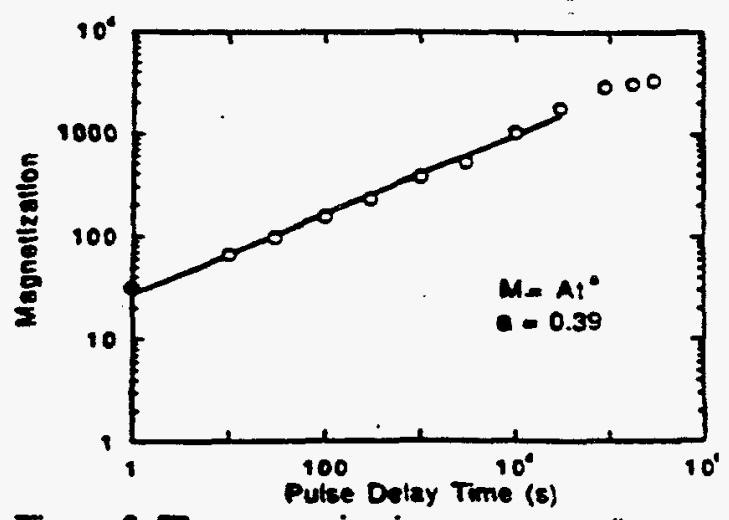

Figure 3. The magnetization recovery of $\alpha$ quatz shocked to $22 \mathrm{GPa}$, which consists of components with differing relaxation behavior.

Figure 2 shows the magnetization recovery for a sample of the unshocked $\alpha$-quarz. The recovery is plotted as a function of pulse delay time on a $\log -\log$ plot, from which it is clear that the magnetization follows a power-law behavior over 5 decades of time. Calibration of the spectrometer with other ailicate samples having shorter relaxation times confirms that the magnetization is near equilibrium for the longest pulse delay times recorded. A least-squares fit to the magnetization data yields a power-law exponent of 0.54 . Figure 3 shows the magnetization recovery of an $\alpha$-quarz sample which has been subjected to a $22 \mathrm{GPa}$ shock wave. The recovery again displays a power-law dependence on pulse delay time, only now the exponent has been reduced to 0.39 .

Naturally-Shocked Ouarz Sandstone; Figure 4 provides the MAS NMR spectra for the 6ve nawrally-shocked samples; numbers in the figures are the same as those used by Kieffer [4]. The spectra are presented in relative order of increasing shock pressure. The ability of MAS NMR to discriminate among the silica polymorphs and amorphous phases is demonstrated by these results. The following is a summary of our observations: Sample \#8: mostly quartz, small amounts of coesite and possibly amorphous silica, no stishovite. Sample \#4: mostly quart2, more coesite than sample \#8, some amorphous silica, and stishovite. Sample \#33: same as sample \#4, but with an additional peak, due to Q3 (one $\mathrm{OH}$ ) silicon sites in a dense form of hydroxylated amorphous silica. Sample \#7: mostly amorphous silica, with some quarz and coesite, no stishovite, contains a less intense peak associated with the same Q3 site as in sample \#33. Sample "9: almost entirely amorphous silica, no stishovite. A representation of the different tetrahedral silicon sites is presented in Figure 5.

\section{DISCUSSION}

Experimentally-Shocked Synthetic Ouartz: By analyzing the spectra of the experimentallyshocked quarz, we were able to estimate the ratio of disordered to ordered phase and determine the fractal dimension of each phase. The spectra of the shocked quartz were numerically fit with two components: a narow Lorentzian component corresponding to an ordered crystalline phase and a broad Gaussian component corresponding to a disordered phase. A Lorentzian lineshape provides the best fit for the entire spectrum of the unshocked material as well as the best fit for the narrow component of the shocked material. A Gaussian lineshape provides the best fit for the broad component of the shocked material. Figure 6 shows the relative intensity of each component as a function of pulse delay time. As stated earlier, each component can be described with a power-law pulse delay time dependence. The exponent of the broad Gaussian component equal to 0.32 and the exponent of the narrow Lorentzian component equal to 0.49 .

Power-law behavior of the magnetization recovery has been observed previously for paramagnetically doped sol-gel derived silicate samples [5]. Power-law dependence for spin-1/2 nuclei is 


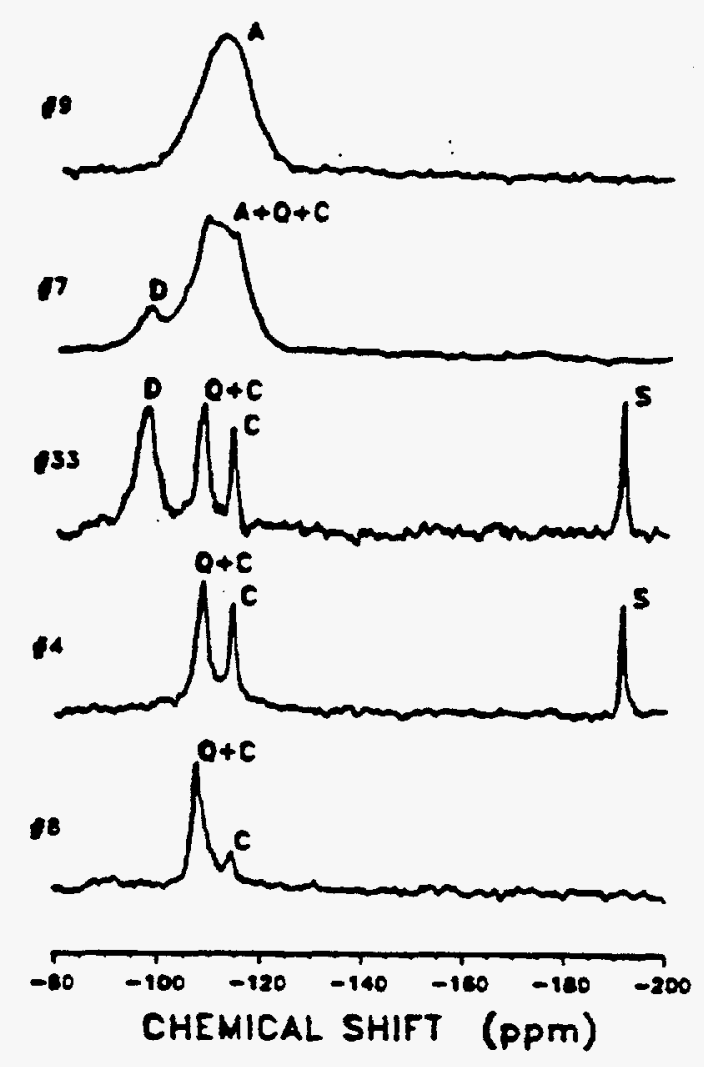

Figure 4. Si-29 NMR spectra of shocked sandstone, where $Q=$ quartz, $C=$ coesite, $S=$ stishovite, $A=$ amorphous ( $Q 4$ sites), and $D=d e n s i f i e d$ form of hydroxylated amorphous silica (Q3 sites). Sample numbers are those of Kieffer [4].<smiles>COC(O)(O)OCO[Si](O)(OC)OCOC(O)(OC)OC</smiles>

Figure 5. Silicon sites that are distinguished by Si-29 NMR spectroscopy using MAS and CPMAS methods

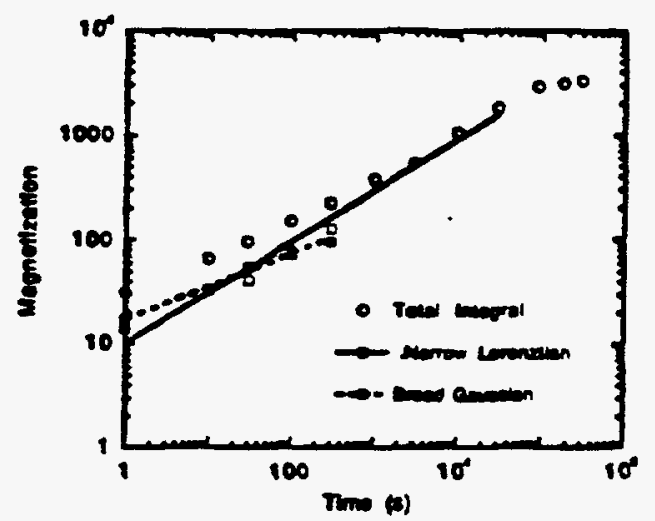

Figure 6. Magnetization recovery of $\alpha$-quartz sample shocked to $22 \mathrm{GPa}$. Each spectrum was deconvolved into a narrow Lorentzian (ordered phase) and a broad Gaussian (disordered phase) component.

expected whenever the sample is undergoing MAS and its relaxation is dominated by randomly-distributed paramagnetic impurities. Although the samples in this study were not intentionally doped, they contain low levels of paramagnetic impurities [6]. The power-law exponent was shown by Devreux et al. [5] to be equal to 1/6 of the fracts dimension of the material containing the observed nuclei. The power-law exponent of 0.54 for unshocked quartz is reasonably close to the value of 0.50 predicted for a three-dimensional material. The nartow Lorentzian component, corresponding to relatively undisturbed crystalline material, has a power-law exponent of 0.49 -consistent with relaxation controlled by a three-dimensional morphology. By contrast, the power-law exponent of 0.32 for the broad Gaussian component is suggestive of relaxation in a two-dimensional system, implying the amorphous phase is lamellar in structure.

The equilibrium intensities of each component are proportional to the amounts of material in each phase. For times of $10,000 \mathrm{~s}$ and above, the broad resonance was a fairly minor component of the wat signal and could be ignored. Thus, a reasonable estimation can be made of the equilibrium signal corresponding to the ordered phase. The intensity of the equilibrium signal corresponding to the disordered phase can not be quantitatively determined; however, because the spectra were difficult to fit in the 1000 to $3000 \mathrm{~s}$ time regime. We estimate that the disordered phase accounts for less than $10 \%$ of the shocked quarz.

Naturally-Shocked Quariz Sandstone: Of particular interest in these results are the strong stishovite resonances in samples \#4 and \#33; the stishovite peak observed by Yang et al. [7] is significantly weaker. We also observe a more intense $X$-ray diffraction line $\left(2 \theta=30.2^{\circ}\right)$ for stishovite, implying 
there is more of this phase in our samples. The only samples for which we observe stishovite are those from the intermediate shock pressures.

The presence of the resonance with a chernical shift of about -98 ppro in two of our samples (\#33 and "7) is especially noteworthy. There is no X-rny diffraction evidence for significant amounts of any crystalline material other than the three silica polymorphs. There are severd lines of evidence that this resonance corresponds to silicon in tetrahedra with one hydroxyl group in a dense form of hydroxylated anorphous silica: 1) Variable recycle time NMR experiments indicate the resonance has a very short relaxation time $\left(T_{1}\right)$, consistent with previous observations for shock-produced amorphous silica 2) The shift to higher frequency (smaller negative ppm value) is consistent with a denser phase than a similar phase formed at one atmosphere for a given silicon coordination. A dense armorphous phase has been identifed in NMR spectra obtained by Nellis et al. [8] from crystalline quartz shocked to $33 \mathrm{GPa}$, with a resonance centered at about $-106 \mathrm{ppm}$, an upfield shift of about $6 \mathrm{ppm}$ from -112 ppra for normal-density silicon glass [9]. The resonance for Q3 (one OH) silicon sites in a normal-density gel is at about -102 ppm [10]. Our observed peak position of about -98 ppm would be consistent with densification by roughly the same amount as the amorphous silica associated with chocked quartz. 3) The peak is broad, indicating a wide range of Si-O-Si bond angles typical of amorphous material, and is inconsistent with silicon in clay or feldspar. 4) The target Coconino Sandstone was weh and there is TEM evidence for vesicular "froth" (consisting of amorphous material produced by stean separation) in the intermediate shock samples [11]. 5) We have observed in a previous NMR ctudy of clinoptilolite that shock loading can generate hydroxyl groups [12].

The strongest evidence for the existence of a densified form of hydroxylated amorphous silica is provided by cross-polarization NMR experiments, referred to as CPMAS when using magic-angle spinning. Cross polarization transfers nuclear spin from protons to other NMR-active nuclei, thereby providing additional structural information and preferentially eliminating spectrum signal from anhydrous phases. Figure 8 provides a comparison of the CPMAS and MAS spectra for sample \#33. The enhanced CPMAS signal for the $-98 \mathrm{pprr}$ resonance confirms the occurrence of the hydroxylated tetnhedral silicon (identified as Q3). A less intense peak at -86 ppm associated with Q2 silicon is also observed in the CPMAS spectrum. No signifcant CPMAS signal is observed for sample "9; the " $A$ " peak is due to $Q 4$ silicon in amorphous silica.

\section{CONCLUSIONS}

The silicon-29 NMR spectra of experimenally-shocked synthetic quarz consist of two components corresponding to ordered and disordered phases. The spin-lattice relaxation of each phase exhibits power-law behavior which suggests that the disordered phase has a two dimensional morphology while the ordered phase is three dimensional. The relative intensities of the fully relaxed spectra yield relative abundances of each phase; by this means, we found that the disordered phase accounts for less than 10\% of the total material.

Silicon-29 NMR spectroscopy can also provide considerable microstructural informaion on high pressure crystalline and amorphous phases resulting from natural impacts. Cross-polarization techniques can be used to enhance silicon resonances near protons to analyze hydrated phases. Using this approach

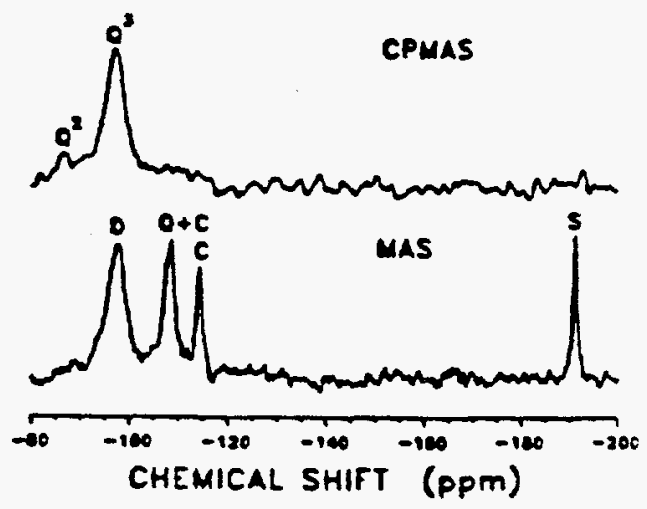

Figure 8. MAS and CPMAS SI-29 NMR spectra for Meteor Crater sample \#33 exhibiting the hydroxylated Q3 and Q4 sites for silicon. 
we have identified a new maturlly-occurring shock-produced phase-a densified hydroxylated amorphous silica.

It is clear from these results that solid state NMR is an exuremely powerful tool for examination of shock-induced microstructural changes in quart, yielding quantitative information on existence of phases, their relative abundances, morphology, and relaxation behavior. Application of similar NMR spectroscopic techniques to the examination of shock-induced microstructural changes in other inorganic compounds-particularly structural ceramics-would be likely to yield sirnilarly useful informa. tion.

\section{ACKNOWLEDGMENTS}

This work was performed at Sandia National Laboricories, supported by the Department of Energy under contract DE-AC0494AL85000, with partial funding by the National Aeronautics and Space Administration's Planetary Materials and Geochemistry program. Susan Kieffer and John McHone kindly provided us with well-documented samples from Meteor Crater. Gary Tumer obtained the NMR spectre on the shocked sandswone.

\section{REFERENCES}

[1] R. T. Cygan, M. B. Boslough, and R. J. Kirkpatrick, "NMR spectroscopy of experimentally chocked quartz: Shock wave barometry," in Proceedings of the Twentieth Lunar and Planetary Science Conference, 1990, pp. 451-457.

[2] R. T. Cygan, M. B. Boslough, and R. J. Kirkpatrick, "NMR spectroscopy of experimentally shocked quartz and plagioclase feldspar powders," in Proceedings of the Lunar and Planetary Science Conference, Volume 22, 1992, pp. 127-136.

[3] R. A. Graham and D. M. Webb, in Shock Woves in Condensed Matter, Y. M. Gupta, ed., New York, Plenum, 1985, pp. 831-36.

[4] S. W. Kieffer, Joumal of Geophysical Research 76, pp. $5449-5473$ (1971).

[5] F. Devreux, J. P. Boilot, F. Chaput, and B. Sapoval, Physical Review Letrers 65, 614 (1990).

[6] E. L. Venturini, private communication.

[7] W.-H. Yang, R. J. Kirkpatrick, N. Vergo, J. McHone, T. I. Emilsson, and E. Oldfield, Meteoritics 21, pp. 117-124 (1986).

[8] W. J. Nellis, A. J. Gratz, P. S. Fiske, and J. F. Stebbins, Eos 73, p. 594 (1992).

[9] R. Oestrike, W.-H. Yang, R. J. Kirkpatrick, R. L. Hervig, A. Navrotsky, B. Montez, Geochimica et Cosmochimica Acto 51, pp. 2199-2209 (1987).

[10] B. Pfleiderer, K. Aber, E. Bayer, L. van de Ven, J. de Haan, and C. Cramers, Joumal of Physical Chemistry 94, pp. 4189-4194 (1990).

[11] S. W. Kieffer, P. P. Phakey, and J. M. Christie, Contributions zo Mineralogy and Petrology 59, pp. $41-93$ (1976).

[12] R. T. Cygan, M. B. Boslough, and R. J. Kirkpatrick, Eos 73, p. 360 (1992). 


\title{
NMR SPECTROSCOPIC EXAMINATION OF SHOCKED SANDSTONE FROM METEOR CRATER, ARIZONA
}

\author{
Randall T. Cygan and Mark B. Bosiough \\ Sandia National Laboratories \\ Albuquerque, NM 87185 \\ R. James Kirkpatrick \\ University of Illinois \\ Urbana, Il 61801
}

Solid state silicon-29 nuclear magnetic resonance (NMR) spectroscopy has been used to characterize the formation of high pressure silica polymorphs and amorphous material associated with the shocked Coconino Sandstone from Meteor Crater, Arizona. Five samples of the sandstone were obtained from several locations at the crater to represent a range of shock conditions associated with the hypervelocity impact of a $30 \mathrm{~m}$-diameter meteorite. The NMR spectra for these powdered materials exhibit peaks assigned to quartz, coesite, stishovite, and glass. A new resonance in two of the moderately shocked samples is also observed. This resonance has been identified as a densified form of amorphous silica with silicon in tetrahedra with one hydroxyl group. Such a phase is evidence for a shock-induced reaction between quartz and steam under high pressure conditions.

\section{INTRODUCTION}

We have applied solid state ${ }^{29} \mathrm{Si}$ nuclear magnetic resonance (NMR) spectroscopy to five naturally-shocked Coconino Sandstone samples from Meteor Crater, Arizona, with the goal of examining possible correlations between NMR spectral characteristics and shock level. This study follows our observation of a strong correlation between the width of a $29 \mathrm{Si}$ resonance and peak shock pressure for experimentally shocked quartz powders $[1,2]$. The peak width increase is due to the shock-induced formation of amorphous silica, which increases as a function of shock pressure over the range that we studied $(7.5$ to $22 \mathrm{GPa})$.

We have previously suggested that NMR spectra be used as a "shock barometer", or at least as an identification technique for shocked quartz. However, our measurements to date have been limited to laboratory-shocked samples. Because the duration of shock loading can be many orders of magninde longer for large impacts, major differences are to be expected. To address these possible differences, we have now turned our attention to naturally-shocked samples. Application of solid state NMR spectroscopy to such samples has been limited. Smith and Blackwell [3] measured spectra of coesite and stishovite from shocked Coconino Sandstone as pan of a comparative study of silica polymorphs. Yang et al. [4] showed that this technique is very sensitive to high-pressure silica phases from whole rock samples of shocked Coconino Sandstone, and is capable of yielding accurate coesite/stishovite ratios. McHone et al. [5] applied the technique to samples collected from the $K / T$ boundary and reported the detection of trace amounts of stishovite, although this interpretation has been disputed [6]. 
Kieffer [7]. The spectra are presented in relative order of increasing shock pressure. Resonance frequencies are provided in terms of chemical shift (ppm relative to an external standard) and are related to the local bonding environment of silicon in different coordinations and to the Si-O-Si bond angle distribution. The ability of MAS NMR to discriminate among the silica polymorphs and amorphous phases is demonstrated by these results.

The following is a summary of our observations: Sample \#8: mostly quartz, small amounts of coesite and possibly amorphous silica, no stishovite. Sample \#4: mostly quartz, more coesite than sample \#8, some amorphous silica, and stishovite. Sample \#33: same as sample \#4, but with an additional peak, due to $\mathrm{Q}^{3}$ (one $\mathrm{OH}$ ) silicon sites in a dense form of hydroxylated amorphous silica. Sample \#7: mostly amorphous silica, with some quartz and coesite, no stishovite, contains a less intense peak associated with the same $\mathrm{Q}^{3}$ site as in sample \#33. Sample \#9: almost entirely amorphous silica, no stishovite. A representation of the different tetrahedral silicon sites is presented in Figure 2.

\section{DISCUSSION}

Of particular interest in these results are the strong stishovite resonances in samples \#4 and \#33; the stishovite peak observed by Yang et al. [4] is significantly weaker. We also observe a more intense $X$-ray diffraction line $\left(2 \theta=30.2^{\circ}\right)$ for stishovite, implying there is more of this phase in our samples. The only samples for which we observe stishovite are those from the intermediate shock pressures.

The presence of the resonance with a chemical shift of about $-98 \mathrm{ppm}$ in two of our samples (\#33 and \#7) is especially noteworthy. There is no $X-$ ray diffraction evidence for significant amounts of any crystalline material other than the three silica polymorphs. There are several lines of evidence that this resonance corresponds to silicon in tetrahedra with one hydroxyl group in a dense form of hydroxylated amorphous silica: 1) Variable recycle time NMR experiments indicate the

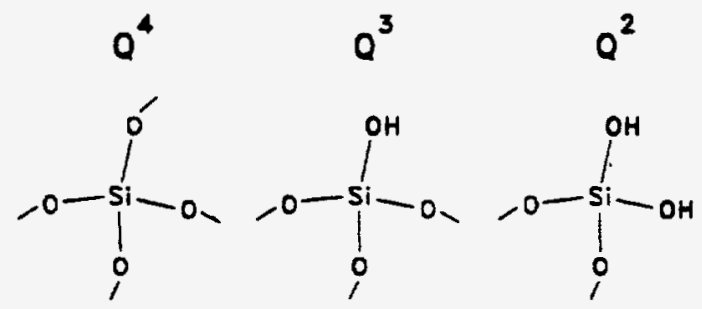

Figure 2. Silicon sites that are distinguished by ${ }^{29} \mathrm{Si}$ NMR spectroscopy using MAS and CPMAS methods.

resonance has a very shor relaxation time $\left(T_{1}\right)$, consistent with previous observations for shockproduced amorphous silica. 2) The shift to higher frequency (smaller negative ppm value) is consistent with a denser phase than a similar phase formed at one atmosphere for a given silicon coordination. A dense amorphous phase has been identified in NMR spectra obtained by Nellis et al. [8] from crystalline quartz shocked to $33 \mathrm{GPa}$, with a resonance centered at about $-106 \mathrm{ppm}$, an upfield shift of about $6 \mathrm{ppm}$ from $-112 \mathrm{ppm}$ for normaldensity silicon glass [9]. The resonance for $Q^{3}$ (one $\mathrm{OH}$ ) silicon sites in a normal-density gel is at about -102 ppm [10]. Our observed peak position of about $-98 \mathrm{ppm}$ would be consistent with densification by roughly the same amount as the amorphous silica associated with shocked quartz. 3) The peak is broad, indicating a wide range of SiO-Si bond angles typical of amorphous material, and is inconsistent with silicon in clay or feldspar. 4) The target Coconino Sandstone was wet, and there is TEM evidence for vesicular "froth" (consisting of amorphous material produced by steam separation) in the intermediate shock samples [11]. 5) We have observed in a previous NMR study of clinoptilolite that shock loading can generate hydroxyl groups [12].

The strongest evidence for the existence of a densified form of hydroxylated amorphous silica is provided by cross-polarization NMR experiments, referred to as CPMAS when using magic-angle spinning. Cross polarization transfers nuclear spin from protons to. other NMR-active nuclei, thereby providing additional structural information and 
Kieffer [7]. The spectra are presented in relative order of increasing shock pressure. Resonance frequencies are provided in terms of chemical shift (ppm relative to an extemal standard) and are related to the local bonding environment of silicon in different coordinations and to the Si-O-Si bond angle distribution. The ability of MAS NMR to discriminate among the silica polymorphs and amorphous phases is demonstrated by these results.

The following is a summary of our observations: Sample \#8: mostly quartz, small amounts of coesite and possibly amorphous silica, no stishovite. Sample \#4: mostly quartz, more coesite than sample \#8, some amorphous silica, and stishovite. Sample \#33: same as sample \#4, but with an additional peak, due to $\mathrm{Q}^{3}$ (one $\mathrm{OH}$ ) silicon sites in a dense form of hydroxylated amorphous silica. Sample \#7: mostly amorphous silica, with some quanz and coesite, no stishovite, contains a less intense peak associated with the same $\mathrm{Q}^{3}$ site as in sample \#33. Sample \#9: almost entirely amorphous silica, no stishovite. A representation of the different tetrahedral silicon sites is presented in Figure 2.

\section{DISCUSSION}

Of particular interest in these results are the strong stishovite resonances in samples \#4 and \#33; the stishovite peak observed by Yang et al. [4] is significantly weaker. We also observe a more intense $X$-ray diffraction line $\left(2 \theta=30.2^{\circ}\right)$ for stishovite, implying there is more of this phase in our samples. The only samples for which we observe stishovite are those from the intermediate shock pressures.

The presence of the resonance with a chemical shift of about $-98 \mathrm{ppm}$ in two of our samples (\#33 and \#7) is especially noteworthy. There is no Xray diffraction evidence for significant amounts of any crystalline material other than the three silica polymorphs. There are several lines of evidence that this resonance corresponds to silicon in tetrahedra with one hydroxyl group in a dense form of hydroxylated amorphous silica: 1) Variable recycle time NMR experiments indicate the<smiles>CO[Si](O)(O)OCO[Si](O)(OC)OCO[Si](O)(OC)OC</smiles>

Figure 2. Silicon sites that are distinguished by ${ }^{29}$ Si NMR spectroscopy using MAS and CPMAS methods.

resonance has a very short relaxation time $\left(T_{1}\right)$, consistent with previous observations for shockproduced amorphous silica. 2) The shift to higher frequency (smaller negative ppm value) is consistent with a denser phase than a similar phase formed at one atmosphere for a given silicon coordination. A dense amorphous phase has been identified in NMR spectra obtained by Nellis et al. [8] from crystalline quartz shocked to $33 \mathrm{GPa}$, with a resonance centered at about $-106 \mathrm{ppm}$, an upfield shift of about $6 \mathrm{ppm}$ from $-112 \mathrm{ppm}$ for normaldensity silicon glass [9]. The resonance for $Q^{3}$ (one $\mathrm{OH}$ ) silicon sites in a normal-density gel is at about -102 ppm [10]. Our observed peak position of about $-98 \mathrm{ppm}$ would be consistent with densification by roughly the same amount as the amorphous silica associated with shocked quartz. 3) The peak is broad, indicating a wide range of Si$\mathrm{O}-\mathrm{Si}$ bond angles typical of amorphous material, and is inconsistent with silicon in clay or feldspar. 4) The target Coconino Sandstone was wet, and there is TEM evidence for vesicular "froth" (consisting of amorphous material produced by steam separation) in the intermediate shock samples [11]. 5) We have observed in a previous NMR study of clinoptilolite that shock loading can generate hydroxyl groups [12].

The strongest evidence for the existence of a densified form of hydroxylated amorphous silica is provided by cross-polarization NMR experiments, referred to as CPMAS when using magic-angle spinning. Cross polarization transfers nuclear spin from protons to other NMR-active nuclei, thereby providing additional structural information and 
preferentially eliminating spectrum signal from anhydrous phases. Figure 3 provides a comparison of the CPMAS and MAS spectra for sample \#33. The enhanced CPMAS signal for the $-98 \mathrm{ppm}$ resonance confirms the occurrence of the hydroxylated tetrahedral silicon (identified as $\mathrm{Q}^{3}$ ). A less intense peak at $-86 \mathrm{ppm}$ associated with $\mathrm{Q}^{2}$ silicon is also observed in the CPMAS spectrum. No significant CPMAS signal is observed for sample \#9; the " $A$ " peak is due to $Q^{4}$ silicon in amorphous silica.

\section{SUMMARY}

Silicon-29 NMR spectroscopy can provide considerable microstructural information on high pressure crystalline and amorphous phases resulting from natural impacts. Cross-polarization techniques can be used to enhance silicon resonances near protons to analyze hydrated phases. Using this approach we have identified a new naturally-occurring shock-produced phase-a densified hydrated amorphous silica.

\section{ACKNOWLEDGMENTS}

Susan Kieffer and John McHone kindly provided us with well-documented samples from Meteor Crater. Gary Turner obtained the NMR spectra. This work was supported by the Dept. of Energy under contract DE-AC04-76DP00789, with partial funding by NASA's PMG program.

\section{REFERENCES}

[1] R. T. Cygan, M. B. Boslough, and R. J. Kirkpatrick, "NMR spectroscopy of experimentally shocked quartz: Shock wave barometry," in Proceedings of the Twentieth Lunar and Planetary Science Conference, 1990, pp. 451-457.

[2] R. T. Cygan, M. B. Boslough, and R. J. Kirkpatrick, "NMR spectroscopy of experimentally shocked quartz and plagioclase feldspar powders," in Proceedings of the Lunar and Planetary

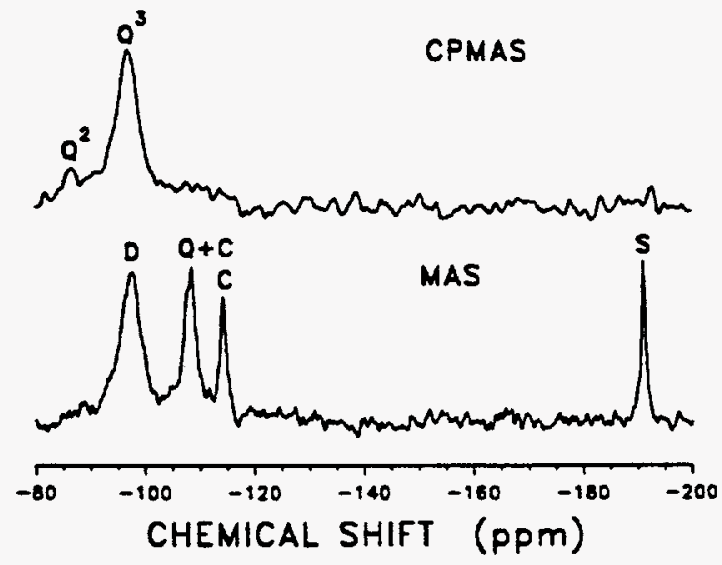

Figure 3. MAS and CPMAS ${ }^{29} \mathrm{Si}$ NMR spectra for Meteor Crater sample \#33 exhibiting the hydroxylated $Q^{3}$ and $Q^{2}$ sites for silicon.

Science Conference, Volume 22, 1992, pp. 127-136.

[3] J. V. Smith and C. S. Blackwell, Narure 303, pp. 223-225, (1984).

[4] W.-H. Yang, R. J. Kirkpatrick, N. Vergo, J. McHone, T. 1. Emilsson, and E. Oldfield, Meteoritics 21, pp. 117-124 (1986).

[5] J. F. McHone, R. A. Nieman, C. F. Lewis, and A. M. Yates, Science 243, pp. 11821184 (1989).

[6] G. A. Izett, Geological Society of Anerica Special Paper 249, p. 1-100 (1990).

[7] S. W. Kieffer, Journal of Geophysical Research 76, pp. 5449-5473 (1971).

[8] W. J. Nellis, A. J. Gratz, P. S. Fiske, and J. F. Stebbins, Eos 73, p. 594 (1992).

[9] R. Oestrike, W.-H. Yang, R. J. Kirkpatrick, R. L. Hervig, A. Navrotsky, B. Montez, Geochimica et Cosmochimica Acta 51, pp. 2199-2209 (1987).

[10] B. Pfleiderer, K. Albert, E. Bayer, L. van de Ven, J. de Haan, and C. Cramers, Journal of Physical Chemistry 94, pp. 4189-4194 (1990).

[11] S. W. Kieffer, P. P. Phakey, and J. M. Christie, Contributions to Mineralogy and Petrology 59, pp. 41-93 (1976).

[12] R. T. Cygan, M. B. Boslough, and R. J. Kirkpatrick, Eos 73, p. 360 (1992). 
NMR SPECTROSCOPY OF EXPERIMENTALLY-SHOCKED COCONINO SANDSTONE AND THE EFFECT OF PORE WATER; R. T. Cygan ${ }^{1}$ M. B. Boslough ${ }^{1}$, and R. J. Kirkpatrick ${ }^{2}$, ${ }^{1}$ Sandia National Laboratories, Albuquerque, NM 87185 and 2University of Illinois, Urbana, IL 61801

We have extended our solid state ${ }^{29}$ Si nuclear magnetic resonance (NMR) spectroscopic study of shocked Coconino Sandstone from Meteor Crater, Arizona. Previously we showed that the NMR spectra of naturally-shocked samples taken from the crater are in excellent agreement with the classification scheme of Kieffer [1], and we identified a new hydroxylated amorphous phase [2,3]. To follow up that work, we have now collected data on Coconino Sandstone explosively shocked to independently-known pressure-temperature states. In addition, we performed identical explosive loading experiments on water-saturated samples to characterize the effects of groundwater in a natural impact. The magic-angle spinning (MAS) spectra for the shocked sandstone powders exhibit no additional phases; resonances for coesite and stishovite are not observed. However, a broadening of the quartz resonance is exhibited for both dry and wet samples relative to the narrow resonance for quartz in the unshocked material. The cross-polarization magic-angle spinning (CPMAS) NMR experiments exhibit an enhanced single resonance, probably associated with hydroxylated silicon in kaolinite clay. This peak broadens with shock-loading for both dry and wet samples. There is no clear distinction between the NMR spectra obtained for the dry and wet samples recovered from the shock-loading experiments.

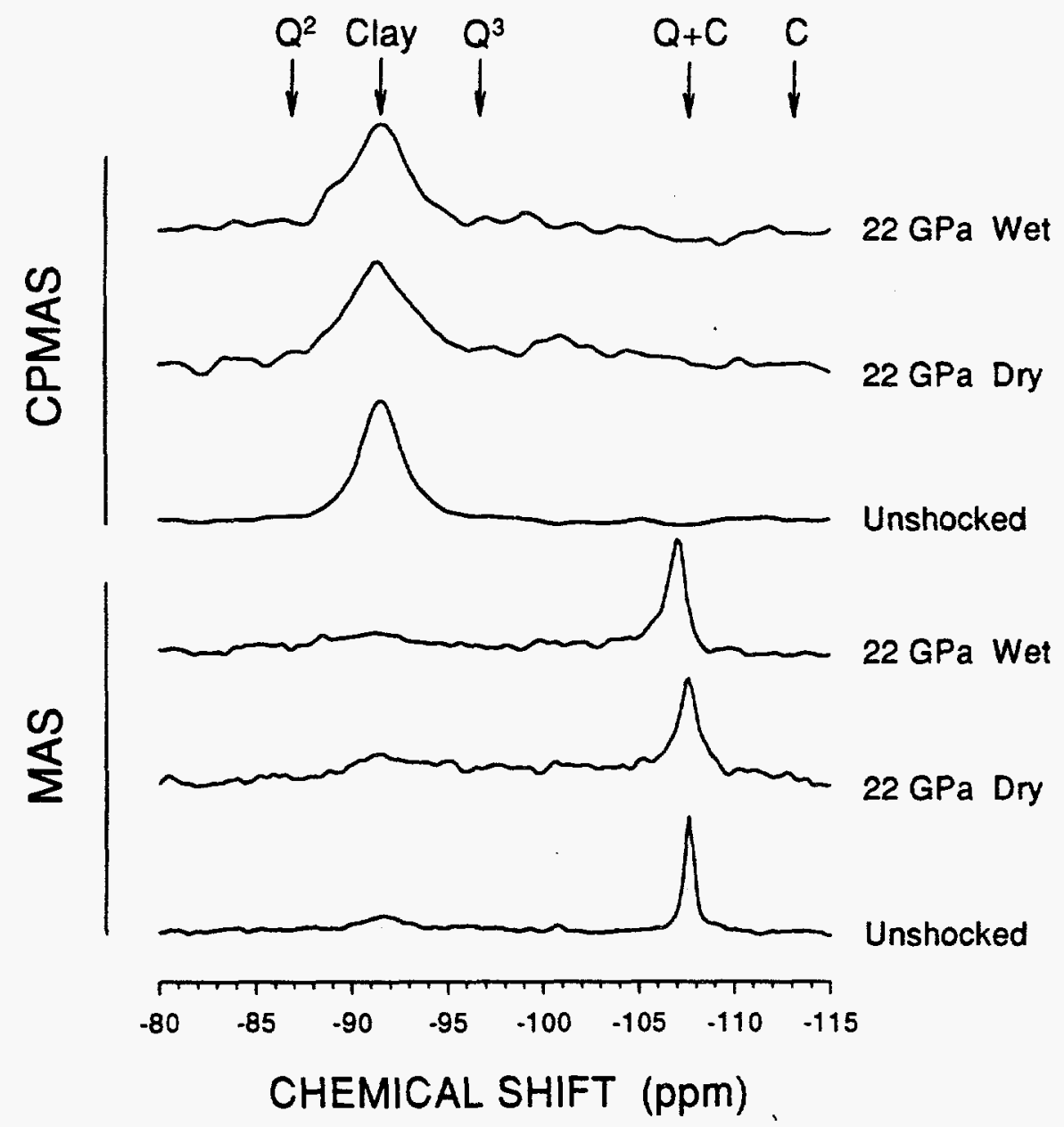

Figure 1. ${ }^{29} \mathrm{Si}$ NMR spectra of unshocked and experimentally-shocked (dry and wet) Coconino Sandstone samples. MAS (all Si sites) and CPMAS (hydrated Si species) spectra are presented for each sample. Arrows denote approximate chemical shift observed in previous studies $[2,3]$ for quartz $(Q)$, coesite $(C)$, clay, and hydrated amorphous silica, including $Q^{3}$ (one $\mathrm{OH}$ ) and $\mathrm{Q}^{2}$ (two $\mathrm{OH}$ ) silicon sites. 
The present work is part of a continuing project to develop solid state NMR spectroscopy as a method of quantifying the effect of shock loading experienced by silicate minerals subjected to natural impact. We have previously suggested that NMR spectra be used as an unambiguous identification technique for shocked quartz, and have shown that it can be used as a "shock barometer" under some conditions [4,5]. In addition to finding a new densified amorphous phase, we have shown that NMR relaxation analysis can provide morphological information about shock-produced amorphous material [6]. However, our measurements to date have been limited to laboratory-shocked synthetic quartz samples, and to naturally-shocked sandstone. Moreover, other workers have obtained quantitatively different results using different starting materials (single crystals as opposed to powder) and different loading conditions [7]. By subjecting Coconino Sandstone to the same shock-loading histories as pure synthetic quartz in our earlier work, we are beginning to bridge the gap between natural and artificial shock-loading histories to help understand the differences. In addition, by using initially water-saturated samples, we attempt to 1) isolate the effect of the presence of water and 2) find out if the dense amorphous hydroxylated phase we found in naturally-shocked sandstone can be synthesized in the laboratory, and if so, under what conditions.

Samples of unshocked Coconino Sandstone were obtained from near Meteor Crater, Arizona and were subjected to explosive loading using the Momma Bear fixtures of Graham and Webb [8]. Wet experiments were performed by first saturating the sandstone powder with deionized water before sealing the copper sample fixture. The dry powder samples were subjected to peak shock pressures of approximately $7.5,16.5$, and $22 \mathrm{GPa}$. The corresponding pressure values for the wet sandstone samples are somewhat higher. The recovered materials were examined by optical and secondary electron microscopies, $X$-ray diffraction, and NMR spectroscopy. We use both standard MAS and CPMAS techniques in the NMR experiments to determine the resonances associated with ${ }^{29}$ Si nuclei. Cross polarization transfers nuclear spin from protons to the $29 \mathrm{Si}$, thereby providing additional structural information and preferentially eliminating spectrum signal produced by anhydrous phases.

The MAS and CPMAS spectra obtained for the shocked sandstone samples do not exhibit any additional resonances compared to the spectra for the unshocked sample (Figure 1). Resonances for coesite $(-108 \mathrm{ppm}$ and $-113 \mathrm{ppm})$ and stishovite $(-192 \mathrm{ppm})$ are not observed. The strong four-fold coordinated silicon resonance, with a chemical shift of $-108 \mathrm{ppm}$, dominates the MAS NMR spectra. A broadening of the quartz resonance for both dry and wet samples is observed with increasing shock pressure. These results are similar to our previous work on dry synthetic quartz powders [4,5]. A minor resonance in the MAS spectra, corresponding to the major resonance in the CPMAS spectra, is observed at $-92 \mathrm{ppm}$. These resonances are associated with the hydroxylated silicon site in clay, probably kaolinite; $X$-ray diffraction analysis of the recovered material contirms this assignment. Some broadening of the clay CPMAS resonance occurs with increasing shock pressure for both dry and wet samples. There is no clear evidence for the formation of a dense hydroxylated amorphous phase in the material recovered from the wet shock-loading experiments. We previously observed for several naturally-shocked samples from Meteor Crater a very strong resonance with a chemical shift of $-97 \mathrm{ppm}$, corresponding to $Q^{3}$ silicon $[2,3]$. These differences in the NMR spectra are related to the distinct loading and unloading histories associated with experimental shock-loading and natural impact events.

References: [1] Kieffer (1971) J. Geophys. Res. 76, 5449-5473. [2] Boslough et al. (1993) Lunar Planet. Sci. XXIV, 149-150. [3] Cygan et al. (1994) In Shock Waves in Condensed Matter-1993, in press. [4] Cygan et al. (1990) in Proc. Lunar Planet Sci. Conf. 20th, 451-457. [5] Cygan et al. (1992) in Proc. Lunar Planet Sci. Conf. 22nd, 127-136. [6] Assink et al. (1994) In Shock Waves in Condensed Matter-1993, in press. [7] Fiske et al. (1993) Lunar Planet. Sci. XXIV, 491-492. [8] Graham and Webb (1984) In Shock Waves in Condensed Matter-1983, 211-214.

Acknowledgments: John McHone and Susan Kieffer were instrumental in helping acquire samples of Coconino Sandstone from Meteor Crater. We thank Meteor Crater Enterprises, Inc. for allowing us access to the crater. Ed Dunbar performed the explosive loading experiments at EMRTC, Socorro, NM. Gary Turner obtained the NMR spectra. This work was partially funded by NASA's PMG program and was performed at Sandia National Laboratories by the U.S. Department of Energy under contract DEAC04-94AL85000. 


\title{
DISTRIBUTION LIST
}

\author{
MS 0821 M. B. Boslough, 1433 (10) \\ MS $0821 \quad$ P. L. Stanton, 1433 \\ MS 0750 R. T. Cygan, 6118 (10) \\ MS $0750 \quad H . R$. Westrich, 6118 \\ MS 0899 Technical Library, 7141 (5) \\ MS 0619 Technical Publications, 7151 \\ MS 0100 Document Processing for DOE/OSTI, 7613-2 (10) \\ MS 9018 Central Technical Files, 8523-2
}

